\title{
Sadism and Aggressive Behavior: Inflicting Pain to Feel Pleasure
}

\author{
David S. Chester ${ }^{1 *}$, C. Nathan DeWall ${ }^{2}$, Brian Enjaian ${ }^{2}$ \\ ${ }^{1}$ Department of Psychology, Virginia Commonwealth University, USA \\ ${ }^{2}$ Department of Psychology, University of Kentucky, USA \\ in press at Personality and Social Psychology Bulletin
}

Main Text Word Count (minus Figures and Tables): 7,928

Abstract Word Count: 143

${ }^{*}$ Correspondence should be addressed to:

David S. Chester

302 Thurston House

Virginia Commonwealth University

Richmond, VA, 23284, USA

1-804-828-7624

dschester@vcu.edu 


\begin{abstract}
Sadism is a 'dark' trait that involves the experience of pleasure from others' pain, yet much is unknown about its link to aggression. Across eight studies (total $N=2,255$ ), sadism predicted greater aggression against both innocent targets and provocateurs. These associations occurred above-and-beyond general aggressiveness, impulsivity, and other 'dark' traits. Sadism was associated with greater positive affect during aggression, which accounted for much of the variance in the sadism-aggression link. This aggressive pleasure was contingent on sadists' perceptions that their target suffered due to their aggressive act. After aggression, sadism was associated with increases in negative affect. Sadism thus appears to be a potent predictor of aggression that is motivated by the pleasure of causing pain. Such sadistic aggression ultimately backfires, resulting in greater negative affect. More generally, our results support the crucial role of anticipated and positive forms of affect in motivating aggression.
\end{abstract}

Keywords: sadism, aggression, dark tetrad, positive affect, emotion 


\section{Introduction}

The wholesome pleasure of prosocial acts must contend with humankind's darker delights. Some people exhibit sadism, which involves "the deliberate infliction of pain for the sake of enjoyment" (pp. 227; Nell, 2006). Sadistic tendencies are not purely the domain of violent criminals but appear among non-clinical and non-criminal populations (Buckels, Jones, \& Paulhus, 2013). Preliminary evidence links sadism to aggression, yet many aspects of sadistic aggression remain incompletely understood. This investigation examined the robustness of the sadism-aggression link across a variety of contexts, targets, and operationalizations of aggression. Further, we examined whether sadists enjoyed the aggressive act and whether the victim's pain caused this aggressive pleasure.

\section{Sadism: The Pleasure of Inflicting Pain}

Sadism is a constellation of personality traits that are characterized by the tendency to enjoy the suffering of others (Baumeister, 1997; Nell, 2006). Rather than passively taking pleasure in others' pain, sadists actively perpetrate harm, motivated by the enjoyment of the aggressive act and the painful outcome (O'Meara, Davies, \& Hammond, 2011). In the past, sadism was as a clinically-diagnosable form of psychopathology, yet such diagnoses have now changed (e.g., sexual sadism disorder; Krueger, 2010). More contemporary approaches to sadism conceptualize it as a continuously-distributed facet of 'dark' personality that extends beyond forensic and clinical samples into the broader distribution of humankind (Buckels et al., 2013; Chabrol, Van Leeuwen, Rodgers, \& Sejourne, 2009; O'Meara et al., 2011). 
Clues about sadism's link to aggression are likely to come from the research on the 'dark triad': Machiavellianism (manipulating others to fulfill selfish goals), Narcissism (holding grandiose and vulnerable views of the self), and psychopathy (sensationseeking and callous disregard for others; Furnham, Richards, \& Paulhus, 2013; Paulhus \& Williams, 2002). The dark triad often predict aggressive traits (Jonason \& Webster, 2010) and acts (e.g., bullying; Baughman, Dearing, Giammarco \& Vernon, 2012). However, the type of aggression is critical to understanding the links between the dark triad and harm-doing. Harming innocent targets in the absence of provocation is deemed proactive aggression, which can be juxtaposed against reactive aggression that takes the form of retaliation against perceived provocateurs (Raine et al., 2006). These forms of aggression are not mutually exclusive and correlate strongly= (Miller \& Lynam, 2006). Narcissism is associated with greater reactive aggression, particularly retaliatory acts in response to ego threats (Bushman \& Baumeister, 1998; c.f. Kirkpatrick, Waugh, Valencia, \& Webster, 2002). Psychopathy is linked to both proactive (Porter \& Woodworth, 2006; Raine et al., 2006) and (to a lesser extent) reactive aggression (Reidy, Zeichner, \& Martinez, 2008; Reidy, Zeichner, Miller, \& Martinez, 2007). When compared in a meta-analytic framework, psychopathy had the strongest association with proactive aggression followed by Machiavellianism, whereas Narcissism was unassociated with proactive aggression (Webster et al., 2014). Some scholars argue that the dark triad form the latent basis of aggressive dispositions and replace the unitary construct of 'trait aggression' (Paulhus, Curtis, \& Jones, 2018). Sadism is considered part of these dark traits, forming a 'dark tetrad' (Paulhus, 2014). 
Although the links between the dark triad and aggression have been well-established, the potential role of sadism in aggression is less understood.

\section{Preliminary Evidence for the Sadism-Aggression Link}

Nascent research has hinted at a link between sadism and aggression. For instance, sadism correlates positively with trait physical aggression and is a core feature of trait revenge-seeking (Chester \& DeWall, 2018). However, such correlations use selfreport instead of overt behavior. Initial research on the relationship between sadism and aggressive behavior focused on the infliction of harm upon innocent targets. For example, sadism is linked to harming insects and innocent humans who refuse to retaliate (Buckels et al., 2013). Implicit sadism was associated with greater electric shocks administered to an innocent target (Reidy, Zeichner, \& Seibert, 2011). Sadism is also uniquely associated with self-reported acts of sexual violence (Russell \& King, 2016), tendencies towards antisocial vices (Jonason, Zeigler-Hill, \& Okan, 2017), as well as self-reports of conventional and online forms of bullying and 'trolling' behavior (Buckels, Trapnell, \& Paulhus, 2014; ; March, Grieve, Marrington, \& Jonason, 2017).

Despite this array of research, further confirmation is necessary to establish sadism's link to aggression. One reason for this uncertainty is that only a handful of studies have assessed sadism's link to actual behavioral measures of aggression. Among these few studies, aggression was operationalized proactively, as the targets of aggression were innocent victims (e.g., Buckels et al., 2013). Aggression is more often reactive than proactive because provocation is the most reliable situational predictor of aggression (Anderson \& Bushman, 2002). Sadism's link to reactive aggression remains uncertain, and therefore, the sadism-aggression link is uncertain. Despite this lack of 
evidence, there are good theoretical reasons to expect that sadism would be associated with reactive aggression, largely centering on the role of positive affect.

\section{The Role of Positive Affect in Aggression}

Traditionally, aggression was theorized to arise from negatively-valenced affective states such as frustration and pain (Berkowitz, 1989). More recently, a wealth of evidence has arisen to support the role of positively-valenced affect in motivating revenge and retaliatory aggressive behavior (Chester, 2017). For example, reading about acts of retaliatory aggression induces positive affect (Eadeh, Peak, \& Lambert, 2016). Actual acts of retaliatory aggression are associated with activity in the brain's reward network (Chester \& DeWall, 2016) and genetic profiles that modulate pleasureseeking (Chester et al., 2015, 2016). This hedonic reward appears to form a positive feedback loop in which acts of violence beget even more acts of violence (Martens, Kosloff, Greenberg, Landau, \& Schmader, 2007). The perceived and ephemeral ability of aggression to regulate and improve aversive affective states further fuels this cyclical aggression (Bushman, Baumeister, \& Phillips, 2001; Chester \& DeWall, 2017;

Gollwitzer \& Bushman, 2012). This positive feedback loop may even explain the development of stable, sadistic tendencies.

Such a positive feedback loop meshes well with the General Aggression Model (Anderson \& Bushman, 2002; DeWall, Anderson, \& Bushman, 2011). Specifically, sadism acts as a personality input variable that increases the likelihood of aggression through the internal route of positive affect. Such a positive, rewarding experience informs appraisal and decision processes when sadists encounter potential victims, making them more likely to engage in impulsive acts. Those impulsive acts, in turn, 
influence how sadists approach their future social encounters, strengthening the knowledge structures that form the basis of how they interpret and react to events in their social world. The next section fleshes out this potential tendency for sadism to experience the pleasure of aggression.

\section{Sadism and the Pleasure of Aggression}

Some individuals are more prone than others to experience the pleasure of aggression and sadism measures are designed to capture this variability (Chester \& DeWall, 2018). Only preliminary evidence exists for sadism's link to aggression-related positive affect (i.e., aggressive pleasure). Sadism was positively-correlated with more enjoyment of killing insects (Buckels et al., 2013) and 'trolling' others online (Buckels, Trapnell, Andjelovic, \& Paulhus, in press; Buckels et al., 2014). However, little evidence links sadism to the pleasure of harming other individuals across proactive and reactive forms of aggression. It also remains uncertain from what aspect of the aggressive act do sadists derive pleasure. Theoretical accounts of sadism invoke the suffering of the victim as the source of aggressive pleasure (Baumeister, 1997; Nell, 2006), yet there is no evidence for this proposal. Such evidence is necessary to determine the very nature of the sadism construct. Further, the timecourse of aggressive pleasure remains uncertain, whether it arises during or after the aggressive act, and how long the feeling lasts after the aggressive act.

\section{Present Research}

To fill these gaps in the literature, the present research tested the over-arching hypotheses that (A \& B) sadism would be associated with greater proactive and reactive aggressive behavior, (C \& D) sadism would be associated with greater positive affect 
during and after the aggressive act, and (E) such aggressive pleasure would be contingent upon the actual suffering of the intended target. In an exploratory fashion, we also examined the role of sadism in negative affect during and after aggressive acts.

To test these hypotheses, we conducted eight studies in which we measured participants' dispositional sadism and gave them an opportunity to act aggressively, either in response to or in the absence of provocation. Many of these studies included measures of negative and positive affect during and after aggression, experimental manipulations of interpersonal provocation, measures of crucial covariates to ensure the specificity of the sadism-aggression link, and variations in the victim's level of suffering due to the aggressive act.

\section{Statistical Power Statement}

Meta-analytic estimates of the mean effect size for aggression studies in personality and social psychology yield $r=.24$ ( $k=3,323$; Richard, Bond, \& Stokes-Zoota, 2003). Therefore, samples of 130 or more participants have at least $80 \%$ power to detect main effects of this magnitude or larger. A priori power analyses were not used to determine the sample sizes in any of the eight studies, though they surpass this sample size threshold (excepting Study 3, $N=126$ ). Some of our more complex inferential tests (e.g., moderation, indirect effects) may be powered below the $80 \%$.

\section{Open Science Statement}

All data files needed to reproduce these results can be publicly-accessed (https://osf.io/fjwhc/files/) and all research materials are available in the associated Methodology Attachment document.

\section{Study 1}


Study 1 tested the hypothesis that sadism would predict greater retaliatory aggression. Participants were provoked and reported their sadism, as well as their trait self-control and impulsivity in order to test whether sadistic aggression is driven by general impulsivity. Psychopathy was also measured in order to assess sadism's link to aggression, above-and-beyond the dark triad (Buckels et al., 2013). To test whether individuals enjoyed the aggressive act, we measured participants' positive and negative affect after the aggression measure.

\section{Methods}

\section{Participants}

Participants were 162 undergraduates (116 females, 42 males, 4 missing gender data).

\section{Materials}

Participants completed the Brief Self-Control Scale (BSCS; Tangney, Baumeister, \& Boone, 2004), positive and negative affect items from the Need Threat Scale (NTS; Williams, 2009), Levenson Self-Report Psychopathy Scale (LSRP; Levenson, Kiehl, \& Fitzpatrick, 1995), Short Sadistic Impulse Scale (SSIS; O'Meara et al., 2011), and the UPPS-P Impulsivity Scale (Lynam, Smith, Whiteside, \& Cyders, 2006; Whiteside \& Lynam, 2001).

\section{Procedure}

This study was part of a larger project on the role of psychostimulants on aggression. Participants arrived at our laboratory where they were randomly assigned to receive either a capsule containing 100mg of caffeine, a placebo capsule, or no capsule. Participants who received a capsule were blind to its contents. Participants 
reported their baseline affective state and watched nature videos for 30 minutes. Participants were then experimentally provoked (as in Pedersen, Gonzales, \& Miller, 2000). To do so, participants were asked to complete a list of difficult and impossible anagrams. The experimenter repeatedly interrupted the participant and expressed frustration with their poor performance, eventually ending the task prematurely. Participants then completed the Taylor Aggression Paradigm (TAP) against another same-gender undergraduate student.

The TAP is a well-validated measure of behavioral, retaliatory aggression framed as a competitive reaction time game played over the internet with a fictitious opponent (Anderson \& Bushman, 1997; Chester \& Lasko, in press; Giancola \& Chermack, 1998; Taylor, 1967). For each of the 17 trials of the task, participants set the volume (60 - 105 decibels) and duration ( $0-5$ seconds) of an aversive noise blast that their opponent ostensibly heard if participants won the competition (i.e., press a button faster). Within the volume and duration settings, responses were coded along a 1 (lowest volume, shortest duration) - 10 (highest volume, longest duration) score gradient. A nonaggression option was also provided (coded as 0 ). The order of participant wins and losses were randomized and then held constant across all participants, excepting when participants failed to respond in time (in which they automatically lost the trial to ensure believability). Participants' opponents always selected the loudest and longest noise blast on the first trial in order to provoke participants. This approach to setting the wins, losses, and opponent's noise blast settings was used in all subsequent studies that employed the TAP. Finally, participants reported their affective state again and then reported their sadism and psychopathy. 


\section{Results}

\section{Descriptive Statistics}

All self-report measures exhibited sufficient internal consistency except the SSIS (Supplemental Table 1), which was largely driven by a single, reverse-scored item "I wouldn't intentionally hurt anyone." We re-calculated the SSIS without this item and performed analyses using the new, 9-item scale (Supplemental Table 1). We averaged volume and duration levels across all 17 trials (as recommended by Chester \& Lasko, in press). Descriptive statistics are summarized in Supplemental Table 1. Zero-order correlations between all study variables are summarized in Supplemental Table 2.

\section{Correlations with Aggressive Behavior}

Sadism was associated with greater aggressive behavior, $r(145)=.25, p=.003$, and this association remained after controlling for trait self-control, primary and secondary psychopathy, and all five facets of impulsivity (Table 1). We used two contrast codes to examine potential effects of the pill condition. The first code contrasted the effect of the caffeine condition (contrast weight: 1) against the placebo condition (contrast weight: -1 ), while not modeling the no pill condition (contrast weight: 0 ). The second code contrasted the effect of taking either the caffeine (contrast weight: 1) or placebo (contrast weight: 1) pill against the no pill condition (contrast weight: -2). Table 1. Sadism's association with aggressive behavior on the Taylor Aggression Paradigm in Study 1. Gender is coded: male=1, female=-1.

\begin{tabular}{lllllll}
\hline Model & Predictor & $\beta$ & $t$ & df & $p$ & $\Delta R^{2}$ \\
\hline 1 & Sadism & .25 & 3.05 & 145 & .003 & \\
2 & Caffeine vs. Placebo Pill & .05 & 0.58 & 143 & .562
\end{tabular}




\begin{tabular}{|c|c|c|c|c|c|c|}
\hline & Pill vs. No Pill & -.07 & -0.79 & 143 & .432 & \\
\hline & Sadism & .23 & 2.85 & 143 & .005 & .05 \\
\hline 3 & Gender & .13 & 1.44 & 144 & .152 & \\
\hline & Sadism & .19 & 2.08 & 144 & .039 & .03 \\
\hline 4 & Caffeine vs. Placebo Pill & .05 & 0.58 & 142 & .564 & \\
\hline & Pill vs. No Pill & -.06 & -0.78 & 142 & 437 & \\
\hline & Self-Control & .00 & 0.05 & 142 & 962 & \\
\hline & Sadism & .23 & 2.78 & 142 & .006 & .05 \\
\hline 5 & Caffeine vs. Placebo Pill & .00 & 0.01 & 141 & .993 & \\
\hline & Pill vs. No Pill & -.04 & -0.48 & 141 & .632 & \\
\hline & Psychopathy - Primary & .19 & 1.86 & 141 & .065 & \\
\hline & Psychopathy - Secondary & .04 & 0.43 & 141 & .669 & \\
\hline & Sadism & .18 & 2.02 & 141 & .045 & .03 \\
\hline 6 & Caffeine vs. Placebo Pill & .03 & 0.30 & 138 & .768 & \\
\hline & Pill vs. No Pill & -.04 & -0.53 & 138 & .596 & \\
\hline & Lack of Perseverance & -.18 & -1.92 & 138 & .057 & \\
\hline & Lack of Premeditation & .00 & 0.01 & 138 & .994 & \\
\hline & Negative Urgency & .11 & 0.83 & 138 & .411 & \\
\hline & Positive Urgency & .02 & 0.17 & 138 & .864 & \\
\hline & Sensation Seeking & .01 & 0.08 & 138 & .935 & \\
\hline & Sadism & .25 & 2.97 & 138 & .004 & .06 \\
\hline
\end{tabular}


Sadism was associated with greater post-aggression negative and positive affect (Supplemental Table 2). After controlling for baseline negative affect, post-aggression negative affect was no longer associated with sadism, $r(125)=.14, p=.126$. After controlling for baseline positive affect, post-aggression positive affect was no longer associated with sadism, $r(125)=-.13, p=.136$.

\section{Study 2}

Study 2 sought to replicate Study 1 using a different aggression measure: the hot sauce paradigm. Study 2 also tested whether sadism was associated with either proactive or reactive aggression or both, and whether sadism's link to such aggression would occur even if participants had to experience the same suffering as their victim.

\section{Methods}

\section{Participants}

Participants were 168 undergraduates (118 females, 47 males, 3 missing gender data). Participants were excluded if they had a relevant food allergy.

\section{Procedure}

Participants arrived at the laboratory where they were randomly assigned to be either socially rejected or accepted via two same-gender students in the Cyberball paradigm (version 4.0; Williams et al., 2012). Next, participants retrospectively reported their negative and positive affect during the Cyberball task using the Need Threat Scale, completed the Short Sadistic Impulse Scale and Self-Report Psychopathy Scale, and then completed the hot sauce aggression paradigm (Lieberman, Solomon, Greenberg, \& McGregor, 1999) against one of their Cyberball partners. Participants were told that they were going to complete a separate study on taste preferences. Each participant 
completed a short questionnaire about their own food preferences, which were supposedly exchanged with one of their Cyberball partners. Participants tasted the hot sauce and then assisted the experimenters by measuring the same hot sauce for one of their Cyberball partners, using the partner's food questionnaire to guide their decision. Just prior to administering the hot sauce to their partner, participants were randomly assigned to be told that they would either have to eat as much hot sauce as they allocated to their Cyberball partner, or not. After allocating the hot sauce to their partner, participants again reported their current negative and positive affect using the Need Threat Scale.

\section{Results}

\section{Descriptive Statistics}

Nineteen participants were excluded from analyses because they previously completed the Cyberball paradigm. All self-report measures exhibited sufficient internal consistency, except the Secondary Psychopathy subscale of the LSRP and the SSIS (Supplemental Table 3), which was again largely driven by the single, reverse-scored item. As in Study 1, we used the SSIS without this item. Hot sauce allocations were positively skewed (skew=3.21) but not zero-inflated (5.4\% zeroes). Therefore we conducted base 10 logarithmic transformations of these values (adding 1 beforehand to ensure that 0 values would still be transformed; as in DeWall, Twenge, Bushman, Im, \& Williams, 2010; Webster \& Kirkpatrick, 2006). This approach reduces problems with skew and kurtosis in aggression data (Chester \& Lasko, in press). Descriptive statistics are summarized in Supplemental Table 3 and zero-order correlations between all study variables are summarized in Supplemental Table 4. 


\section{Correlations with Aggressive Behavior}

Sadism was unassociated with greater hot sauce allocations, $r(147)=.16, p=.053$.

This null effect that was not moderated by the Cyberball manipulation or whether participants believed that they would have to consume as much hot sauce as they allocated to their partner (Table 2). Sadism was unassociated with aggression after controlling for primary and secondary psychopathy (Table 2).

Table 2. Sadism's association with aggressive behavior on the Hot Sauce Aggression Paradigm in Study 2. Gender is coded: male=1, female=-1. Rejection condition is coded: rejection $=1$, acceptance $=-1$.

\begin{tabular}{lllllll}
\hline Model & Predictor & $\beta$ & $t$ & $\mathrm{df}$ & $p$ & $\Delta R^{2}$ \\
\hline 1 & Sadism & .16 & 1.95 & 147 & .053 & \\
\cline { 2 - 7 } 3 & Gender & .19 & 2.27 & 146 & .025 & \\
& Sadism & .12 & 1.48 & 146 & .141 & .01 \\
\cline { 2 - 7 } & Rejection Condition & .17 & 0.65 & 145 & .519 & \\
& Sadism & .13 & 1.38 & 145 & .169 & .02 \\
& Rejection x Sadism & -.22 & -0.82 & 145 & .416 & .00 \\
\cline { 2 - 7 } & Self-Harm Condition & -.04 & -0.17 & 145 & .865 & \\
& Sadism & .16 & 1.90 & 145 & .060 & .03 \\
& Self-Harm x Sadism & .02 & 0.09 & 145 & .925 & .00 \\
\cline { 2 - 7 } 5 & Rejection Condition & -.06 & -0.77 & 143 & .442 & \\
& Self-Harm Condition & -.02 & -0.27 & 143 & .790 & \\
& Psychopathy - Primary & .12 & 1.27 & 143 & .205 & \\
& Psychopathy - Secondary & .11 & 1.19 & 143 & .236 & \\
& & & & & &
\end{tabular}


$\begin{array}{llllll}\text { Sadism } & .07 & 0.69 & 143 & .489 & .00\end{array}$

\section{Correlations with Post-Aggression Affect}

Sadism was significantly associated with greater negative but not positive affect after aggression (Supplemental Table 4). Sadism remained associated with greater negative affect after aggression after controlling for prior negative affect, $r(145)=.20$, $p=.015$. Conversely, sadism remained unassociated with positive affect after aggression after controlling for prior positive affect, $r(145)=-.07, p=.403$.

\section{Study 3}

Study 3 sought to replicate Study 2 using an online aggression measure.

\section{Methods}

\section{Participants}

Participants were 126 undergraduates (62 females, 64 males).

\section{Procedure}

Participants completed the study online, in which they were randomly assigned to be either socially rejected or accepted via two same-gender students in the Cyberball paradigm (version 4.0; Williams et al., 2012). Afterwards, participants retrospectively reported their negative and positive affect during Cyberball via the Need Threat Scale and then completed an image-assignment aggression measure (as in Gollwitzer \& Bushman, 2012). To do so, participants chose the number of "images that depict aversive scenes such as homicide crime scenes, rotting animal carcasses, and traumatic injuries" for one of their Cyberball partners to see (between 0 and 9 images). Participants were randomly assigned to be told that the person who would view these images was either one of their Cyberball partners or a new person (i.e., an innocent 
target). Participants again reported their levels of negative and positive affect via the Need Threat Scale and completed the Short Sadistic Impulse Scale.

\section{Results}

\section{Descriptive Statistics}

Descriptive statistics are summarized in Supplemental Table 5 and zero-order correlations between all study variables are summarized in Supplemental Table 6 .

\section{Correlations with Aggressive Behavior}

Sadism was associated with greater numbers of gruesome images assigned to be viewed by another person, $r(123)=.18, p=.049$. The association between sadism and gruesome image allocation was not moderated by whether participants had been experimentally rejected or whether their aggression was directed at their Cyberball partners or a new person (Table 3).

Table 3. Sadism's association with aggressive behavior in Study 3. Gender is coded: male=1, female=-1. Rejection condition is coded: rejection $=1$, acceptance $=-1$; Retaliatory condition is coded: retaliatory $=1$, non-retaliatory $=-1$.

\begin{tabular}{lllllll}
\hline Model & Predictor & $\beta$ & $t$ & df & $p$ & $\Delta R^{2}$ \\
\hline 1 & Sadism & .18 & 1.99 & 123 & .049 & \\
\cline { 2 - 7 } 2 & Gender & .03 & 0.30 & 122 & .533 & \\
& Sadism & .17 & 1.90 & 122 & .060 & .03 \\
\cline { 2 - 7 } 3 & Rejection Condition & .40 & 1.93 & 121 & .056 & \\
& Sadism & .16 & 1.80 & 121 & .074 & .03 \\
& Rejection x Sadism & -.35 & -1.70 & 121 & .091 & .02 \\
\cline { 2 - 7 } 4 & Retaliatory Condition & -.59 & -2.76 & 121 & .007 &
\end{tabular}




\begin{tabular}{lllllll} 
Sadism & .03 & 0.31 & 121 & .761 & .02 \\
Retaliatory x Sadism & .43 & 2.01 & 121 & .047 & .03 \\
\cline { 2 - 7 } & Rejection Condition & .44 & 1.63 & 117 & .105 & \\
Retaliatory Condition & -.56 & -2.58 & 117 & .011 & \\
Sadism & .03 & 0.30 & 117 & .767 & \\
Rejection x Sadism & -.36 & -1.48 & 117 & .142 & \\
Retaliatory x Sadism & .42 & 1.93 & 117 & .056 & \\
Rejection x Retaliatory & -.19 & -0.62 & 117 & .535 & \\
Rejection x Retaliatory x & .10 & 0.35 & 117 & .730 & .00 \\
Sadism & & & & &
\end{tabular}

\section{Correlations with Post-Aggression Affect}

Sadism was associated with greater negative affect after aggression (Supplemental Table 6), even after controlling for prior negative affect, $r(118)=.24$, $p=.008$. Sadism was not associated with less positive affect after aggression, (Supplemental Table 6), even after controlling for prior positive affect, $r(118)=-.11$, $p=.232$.

\section{Study 4}

Study 4 sought to replicate the previous studies with an array of aggression measures, while also including a measure of affect during the aggressive act.

\section{Methods}

\section{Participants}


Participants were 211 undergraduates (132 females, 73 males, 6 missing gender data $\left.^{1}\right)$.

\section{Measures}

Participants completed the History of Physical Fights Scale (Chester \& Lasko, in press) and an ad hoc questionnaire in which participants retrospectively reported various positively-valenced feelings they experienced during an act of aggression. Such retrospective affect reports are quite accurate (Harmon-Jones, Bastian, \& HarmonJones, 2016) and allowed us to test whether sadism was linked to positive affect in the midst aggression, not just afterwards. Thirty six, positively-valenced items were acquired from the NTS, PANAS, Profile of Mood States (Curran, Andrykowski, \& Studts, 1995), Discrete Emotions Questionnaire (Harmon-Jones et al., 2016), and generated independently by the authors (list of items available in Supplemental Table 7).

Participants retrospectively reported whether they experienced these 36 affective states during the Taylor Aggression Paradigm ("indicate the extent to which this [affective state] described how you felt when your opponent received the noise blasts that you picked in the competitive reaction-time task"). An exploratory factor analysis (EFA) detailed in Study 7 produced a 9-item measure of Aggressive Pleasure from this larger item-set (final items available in Supplemental Table 8). Study 7 was used for this EFA instead of Study 4 given its much larger sample size.

\section{Procedure}

${ }^{1}$ Aggression data from these participants has been reported elsewhere (Chester \& Lasko, in press), but not in the context of sadism. 
Participants arrived individually to the laboratory. In order to experimentallyinduce retaliatory aggression, this study used an essay evaluation paradigm in which participants received harsh or positive feedback on an essay (Bushman \& Baumeister, 1998; Chester \& DeWall, 2017). The essay evaluation contained either negative (8/35 points, "One of the WORST essays l've EVER read!") or positive (33/35 points, "Great essay!") feedback, as determined by random assignment. Participants then completed a 25-trial version the Taylor Aggression Paradigm, which was otherwise identical to the task used in Study 1, the Hot Sauce Aggression Task (as in Study 2), and the Voodoo Doll Aggression Task (VDAT). The VDAT presents participants with a virtual representation of a human target that participants are given an opportunity to symbolically harm that person by harming the doll (DeWall et al., 2013). Participants selected the number of virtual, sharp pins that they wished to stick into a plush human doll as a symbolic representation of their actual essay evaluator (from 0 to 51 pins). Finally, participants completed a battery of questionnaires, which included the Positive Affect During Aggression Scale and the Short Sadistic Impulse Scale

\section{Results}

\section{Descriptive Statistics}

Hot sauce allocations were leptokurtic (kurtosis=2.77) but not zero-inflated (10.3\% zeroes). Voodoo doll pin counts were positively skewed (skew=2.18), leptokurtic (kurtosis $=4.37)$, and zero-inflated (36.9\% zeroes). Therefore we conducted logarithmic transformations of these values (as in Study 2). Because of the extensive zero-inflation in Voodoo Doll pin counts, we adopted generalized linear modeling that specified a Poisson distribution (as recommended by DeWall et al., 2013). This Poisson approach 
was also adopted for reports of violence over the past year and past 5 years from the History of Physical Fights Scale, due to their extensive zero inflation: $65.5 \%$ zeroes and $86.8 \%$ zeroes, respectively. Descriptive statistics are summarized in Supplemental Table 9. Zero-order correlations between all study variables are summarized in Supplemental Table 10. The nine-item version of the SSIS was adopted due to internal consistency issues, as in Studies 1 and 2.

\section{Correlations with Aggressive Behavior and Pleasure}

Sadism was associated with administering louder and longer noise blasts to essay evaluators, $r(180)=.19, p=.011$, though not with greater hot sauce allocations, $r(175)=.06, p=.442$. Using Poisson modeling, sadism was associated with greater voodoo doll pin counts, $B=0.35, X^{2}(1,170)=69.95, p<.001$, and greater frequencies of physical fights over the past five years, $B=1.10, X^{2}(1,180)=54.20, p<.001$, and past year, $B=0.76, X^{2}(1,177)=61.18, p<.001$. The sadism-aggression link was not moderated by prior provocation, excepting the case of voodoo doll pin counts, in which provocation attenuated the effect of sadism on pin counts (Table 4). As evidence for the construct validity of our sadism measure, sadism was associated with greater reports of pleasure during noise blast administration, $r(180)=.19, p=.009$.

Table 4. Sadism's association with aggressive behavior in Study 4. Gender is coded: male=1, female $=-1$. Provocation condition is coded: provoked $=1$, unprovoked $=-1$.

\begin{tabular}{llllllll}
\hline Model & Aggression & Predictor & $\beta$ & $t$ & df & $p$ & $\Delta R^{2}$ \\
& Measure & & & & & & \\
& & & & & & & \\
\hline 1 & Hot Sauce & Sadism & .06 & 0.77 & 175 & .442 &
\end{tabular}


2

3

TAP

5

6

9

\begin{tabular}{lccccc}
\hline Gender & .20 & 2.63 & 174 & .009 & \\
Sadism & .01 & 0.18 & 174 & .861 & .00 \\
& & & & & \\
\hline Provocation Condition & -.05 & -0.21 & 173 & .833 & \\
Sadism & .05 & 0.65 & 173 & .519 & .00 \\
Provocation x Sadism & .05 & 0.23 & 173 & .817 & .00 \\
& & & & & \\
\hline Sadism & .19 & 2.58 & 180 & .011 & \\
\hline Gender & -.11 & -1.43 & 179 & .154 & \\
Sadism & .21 & 2.84 & 179 & .005 & .04 \\
& & & & & \\
\hline Provocation Condition & .29 & 1.41 & 178 & .160 & \\
Sadism & .18 & 2.34 & 178 & .020 & .03 \\
Provocation x Sadism & -.12 & -0.58 & 178 & .586 & .00 \\
\hline Sadism & .14 & 1.83 & 170 & .069 & \\
\hline Gender & & & & & \\
Sadism & -.22 & -2.86 & 169 & .005 & \\
\hline Provocation Condition & .66 & 3.19 & 168 & .002 & \\
Sadism & .19 & 2.44 & 169 & .016 & .03 \\
Provocation x Sadism & -.44 & -2.08 & 168 & .039 & .02 \\
& & & & & \\
\hline
\end{tabular}

Structural Equation Modeling: Estimating Direct and Indirect Effects of Sadism and Aggressive Pleasure on a Latent Form of Aggressive Behavior

We used structural equation modeling to examine whether the pleasure of the aggressive act accounted for the sadism-aggression link (Figure 1). All three aggression measures were modeled onto a latent aggression factor. The two physical fight variables were too zero-inflated to warrant inclusion in this parametric model. Bias- 
corrected bootstrapping was used to estimate the indirect effect and its associated $95 \%$ confidence interval (500 bootstrap samples; via AMOS 24.0 software). The variance of the latent aggression factor was pre-set to 1 to allow for the estimation of all paths.

Overall the model fit the data well, $X^{2}(4)=3.64, p=.458 ; C F I=1.00 ; N F I=0.94$;

RMSEA $=.00(90 \% \mathrm{Cl}=.00, .11) ; T L I=1.02$, though hot sauce allocations failed to significantly load onto the latent aggression factor. Sadism was linked to greater aggressive behavior through greater pleasure during the aggressive act [indirect effect: $B=.05, S E=.03,95 \% C l=.01, .14, p=.013]$. Thus, sadism's link to aggression is explained, in part, by the enjoyment of the aggressive act.

Figure 1. Structural equation model from Study 4 modeling the indirect effect of sadism on aggression via greater aggressive pleasure. Values above paths represent standardized coefficients and values attached to variables represent residual, unstandardized variances. Dashed paths are non-significant. ${ }^{*} p<.05$, ${ }^{* *} p<.01,{ }^{* \star *} p<.001$.

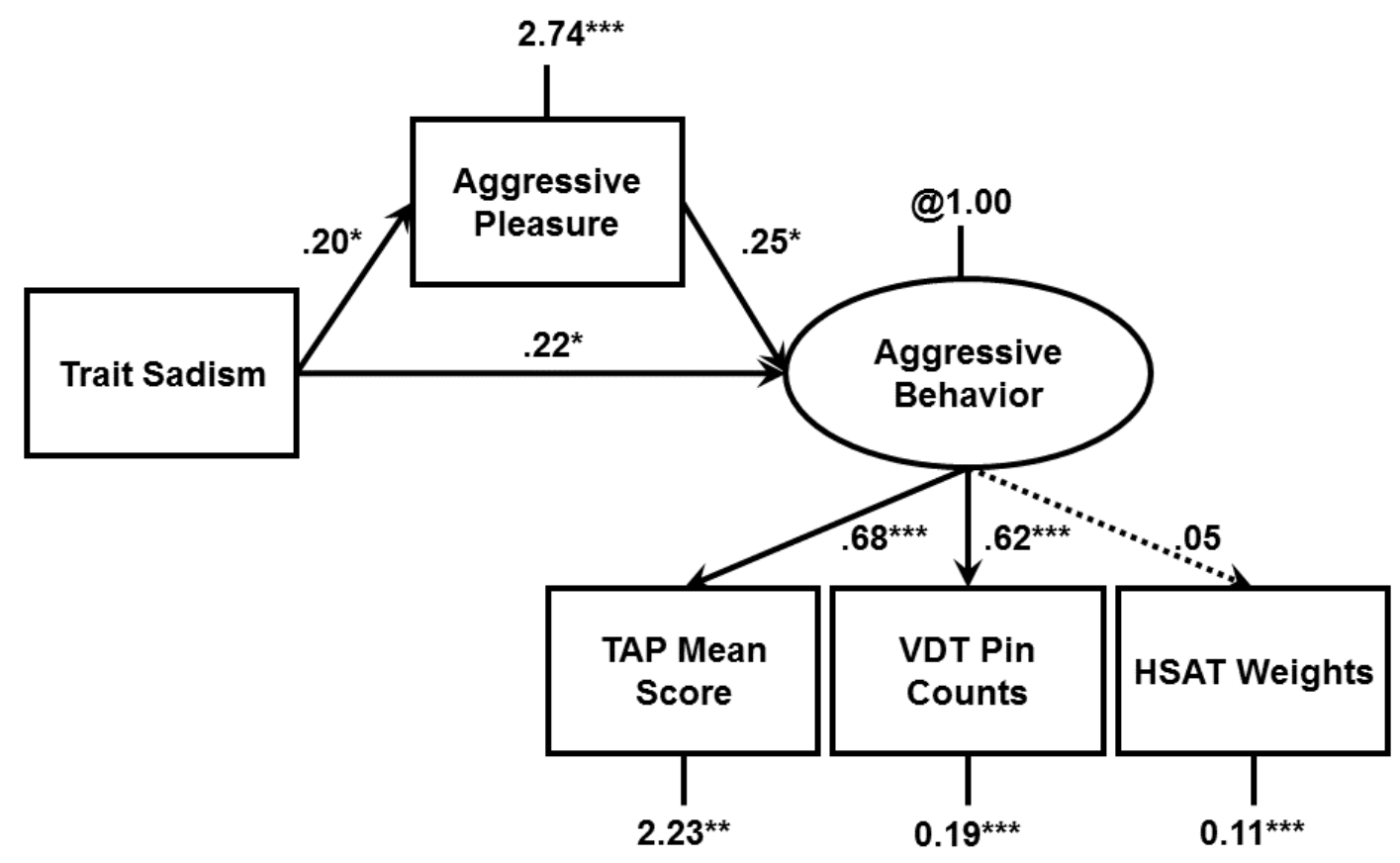




\section{Study 5}

Study 5 sought to replicate the previous studies while including a baseline affect measure that was missing from Study 4 . Without a baseline affect estimate, the results of Study 4 could be due to underlying differences in affect levels between individuals high and low in sadism. Study 5 included measures of negative and positive affect before, during, and after aggression. Study 5 also included a measure of trait aggression as an additional control variable.

\section{Methods}

\section{Participants}

Participants were 156 adult participants recruited from Amazon's Mechanical Turk subject pool (75 females, 80 males, 1 missing gender data). Participants were compensated with $\$ 0.50^{2}$.

\section{Materials}

Participants completed the 12-item Brief Aggression Questionnaire, a short-form of the 29-item Buss-Perry (1982) Aggression Questionnaire (BAQ; Webster et al., 2013).

\section{Procedure}

Participants were randomly assigned to be provoked or not through an online version of the essay-evaluation paradigm employed in Study 4. After the essay task, participants reported their current negative and positive affect using the Need Threat

\footnotetext{
${ }^{2}$ Aggression and affect data from these participants has been reported elsewhere (Chester \& DeWall, 2017), but not in the context of sadism.
} 
Scale, and then completed the Voodoo Doll Aggression Task (target was 'your essay evaluator'). After confirming their pin count, participants retrospectively reported their negative and positive affect experienced during the Voodoo Doll Aggression Task and then reported their current negative and positive affect, in both cases using variants of the Need Threat Scale. Finally, participants completed the Short Sadistic Impulse Scale and Brief Aggression Questionnaire. Embedded in this battery of questionnaires was a single quality check item that asked participants to pick a specific number from a number array.

\section{Results}

\section{Descriptive Statistics}

Three participants failed the quality check and were removed from all subsequent analyses. Voodoo doll pin counts were not excessively skewed (skew=1.54) or kurtotic (kurtosis $=1.02$ ) but they were zero-inflated $(50.3 \%$ zeroes). To address this zeroinflation, we adopted a Poisson analytic approach. Descriptive statistics are summarized in Supplemental Table 11. Zero-order correlations between all study variables are summarized in Supplemental Table 12.

\section{Correlations with Aggressive Behavior}

Sadism was associated with a greater number of pins stuck in the voodoo doll, which remained statistically significant after controlling for gender and the four facets of trait aggression (Table 5). As in Study 4, the effect of sadism on aggression was attenuated by the provocation manipulation (Table 5). 
Table 5. Sadism's association with aggressive behavior on the Voodoo Doll Aggression Task in Study 5. Gender is coded: male=1, female $=-1$. Provocation condition is coded: provoked $=1$, unprovoked $=-1$.

\begin{tabular}{llllll}
\hline Model & Predictor & $B$ & $X^{2}$ & $\mathrm{df}$ & $p$ \\
\hline 1 & Sadism & .37 & 497.89 & 1,150 & $<.001$ \\
\cline { 2 - 6 } & Gender & -.30 & 33.63 & 1,149 & $<.001$ \\
& Sadism & .38 & 520.53 & 1,149 & $<.001$ \\
\cline { 2 - 6 } & Provocation Condition & 2.28 & 311.20 & 1,148 & $<.001$ \\
& Sadism & 0.22 & 131.07 & 1,148 & $<.001$ \\
& Provocation x Sadism & -0.35 & 82.87 & 1,148 & $<.001$ \\
\cline { 2 - 6 } & Provocation Condition & 1.28 & 364.94 & 1,145 & $<.001$ \\
& Anger & 0.05 & 4.01 & 1,145 & .045 \\
& Hostility & 0.25 & 109.24 & 1,145 & $<.001$ \\
& Physical Aggression & 0.14 & 66.98 & 1,145 & $<.001$ \\
& Verbal Aggression & -0.19 & 57.42 & 1,145 & $<.001$ \\
& Sadism & 0.14 & 39.01 & 1,145 & $<.001$ \\
\hline
\end{tabular}

\section{Correlations with Affect During Aggression}

An indirect effect analysis (using 5,000 bias-corrected and accelerated bootstrap samples via the PROCESS macro for SPSS v.3.1, model 4; Hayes, 2012) showed that the direct effect of sadism on log-transformed aggression scores was explained, in part, by positive affect experienced during the aggressive act [indirect effect: $B=0.04$, $S E=0.02,95 \% C l=0.01,0.08]$ but not through negative affect experienced during the aggressive act $[B=-0.00, S E=0.01,95 \% C l=-0.01,0.01]$ (difference between these 
indirect effects, $B=0.04, S E=0.02,95 \% C l=0.01,0.08)$, controlling for post essay feedback negative and positive affect (Figure 2).

Figure 2. Statistical model from Study 5 , modeling the indirect effect of sadism on aggression through greater positive affect during aggression (key paths highlighted in black). Values represent unstandardized regression coefficients, dashed lines represent non-significant effects, value in parentheses is direct effect after controlling for indirect effect, ${ }^{\star} p<.05,{ }^{\star \star} p<.01,{ }^{\star \star \star} p<.001$.

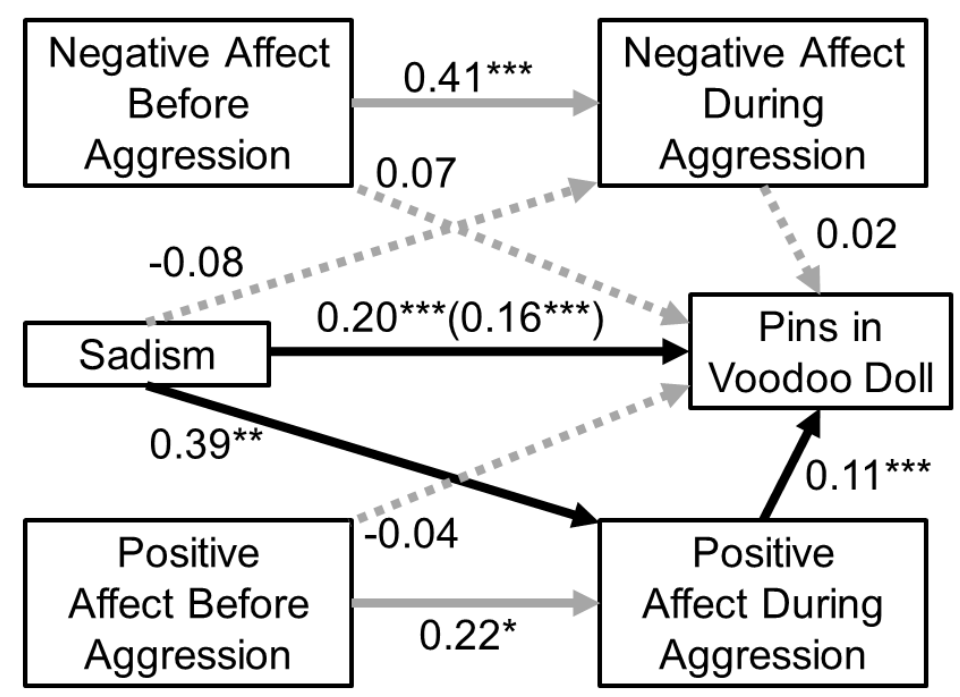

\section{Correlations with Post-Aggression Affect}

Sadism was associated with greater negative affect after aggression (Supplemental Table 12), even after controlling for prior negative affect, $r(149)=.26$, $p=.001$. Sadism was unassociated with positive affect after aggression (Supplemental Table 12), even after controlling for prior positive affect, $r(149)=.06, p=.456$.

\section{Study 6}

Study 6 sought to replicate the previous studies using a different affect measure. Further, Study 6 manipulated self-regulatory fatigue, given evidence linking this experience to heightened aggression (Denson, DeWall, \& Finkel, 2012). 


\section{Methods}

\section{Participants}

Participants were 238 undergraduates (176 females, 62 males).

\section{Materials}

Participants completed the Positive Affect Negative Affect Schedule (PANAS), a validated measure of current levels of positive and negative affect (i.e., mood; Watson, Clark, \& Tellegen, 1988).

\section{Procedure}

Participants arrived at the laboratory where they were randomly assigned to write an essay for 5 minutes about a personally meaningful event. Participants were randomly assigned to not use the letters $\mathrm{X}$ or $\mathrm{Z}$ (control condition) or $\mathrm{A}$ or $\mathrm{N}$ (fatigue condition; as in Mead, Baumeister, Gino, Schweitzer, \& Ariely, 2009). After doing so, participants completed the PANAS and then completed a series of benign, cognitive tasks that were related to a larger project on self-regulation (e.g., Stroop Task). Then, participants completed the Voodoo Doll Aggression Task against an imagined person from participants' real lives that they "feel a great amount of anger towards." Participants again reported their affective state during and after aggression via the PANAS, and then completed the Short Sadistic Impulse Scale.

\section{Results}

\section{Descriptive Statistics}

Voodoo doll pin counts were not excessively skewed (skew=1.49) or kurtotic (kurtosis $=0.98$ ) but they were zero-inflated $(42.2 \%$ zeroes). Because of the extensive zero-inflation, we adopted a Poisson approach. Descriptive statistics are summarized in 
Supplemental Table 13. Zero-order correlations between all study variables are summarized in Supplemental Table 14. The nine-item version of the Short Sadistic Impulse Scale was adopted due to internal consistency issues, as in Studies 1, 2, and 4.

\section{Correlations with Aggressive Behavior}

Aggressive behavior was associated with sadism, which was observed after controlling for gender (Table 6). As in Studies 4 and 5, the sadism-aggression link was attenuated by the study's experimental manipulation, in this case, of self-regulatory fatigue (Table 6).

Table 6. Sadism's association with aggressive behavior on the Voodoo Doll Aggression Task in Study 6. Gender is coded: male=1, female=-1. Fatigue condition is coded: fatigued $=1$, unfatigued $=-1$.

\begin{tabular}{llllll}
\hline Model & Predictor & $B$ & $X^{2}$ & $\mathrm{df}$ & $p$ \\
\hline 1 & Sadism & 0.47 & 233.33 & 1,235 & $<.001$ \\
\cline { 2 - 6 } 2 & Gender & -0.15 & 9.65 & 1,234 & .002 \\
& Sadism & 0.51 & 235.20 & 1,234 & $<.001$ \\
\cline { 2 - 6 } 3 & Fatigue Condition & 0.67 & 43.06 & 1,233 & $<.001$ \\
& Sadism & 0.21 & 18.46 & 1,233 & $<.001$ \\
& Fatigue x Sadism & -0.52 & 69.83 & 1,233 & $<.001$
\end{tabular}

\section{Correlations with Affect During Aggression}

The effect of sadism on aggression, was explained, in part, by positive affect experienced during the aggressive act $[B=0.04, S E=0.03,95 \% C l=0.01,0.10]$ but not through negative affect experienced during the aggressive act $[B=-0.00, S E=0.01,95 \%$ 
$\mathrm{Cl}=-0.03,0.03$ ] (though the difference between these indirect effects was not significant, $B=0.04, S E=0.03,95 \% C l=-0.11,0.01$ ), controlling for baseline affect (Figure 3).

Figure 3. Statistical model from Study 6, modeling the indirect effect of sadism on aggression through greater positive affect during aggression (key paths highlighted in black). Values represent unstandardized regression coefficients, dashed lines represent non-significant effects, value in parentheses is direct effect after controlling for indirect effect, ${ }^{\star} p<.05,{ }^{\star \star} p<.01,{ }^{\star \star \star} p<.001$.

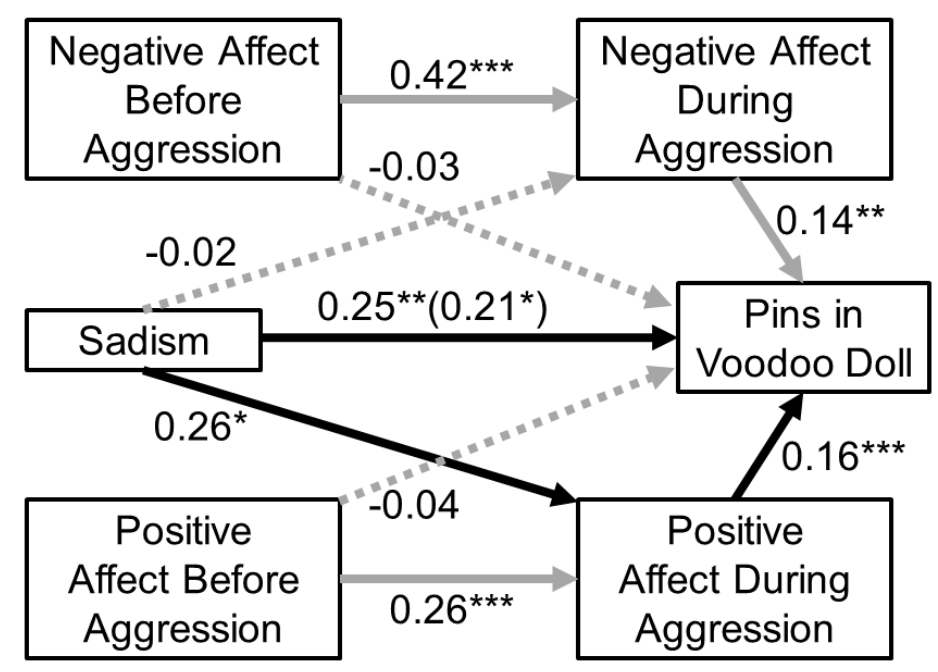

Correlations with Post-Aggression Affect

Sadism was associated with greater negative affect after aggression (Supplemental Table 14), even after controlling for prior negative affect, $r(234)=.16$, $p=.016$. Sadism was unassociated with positive affect after aggression (Supplemental Table 14), even after controlling for prior negative affect, $r(234)=-.03, p=.602$.

\section{Study 7}

Study 7 served to replicate the previous studies employing a rejection manipulation, while also creating a novel state-level measure of pleasure experienced during aggression that was employed in Studies 4, 7, and 8. This study also combined 
multiple measures of sadism (to ensure that our effects were not specific to an individual measure of this construct), as well as assessments of the dark triad, to ensure the existence of the sadism-aggression link above-and-beyond these constructs.

Finally, this study created a novel state-level measure of perceptions that the victim of an aggressive act suffered, in order to investigate the idea that aggressive pleasure is derived directly from the pain inflicted on the victim by the aggressive act.

\section{Methods}

\section{Participants}

Participants were 388 undergraduates (249 females, 134 males).

\section{Materials}

Participants completed the Assessment of Sadistic Personality (ASP; Plouffe, Saklofske, \& Smith, 2017), the Comprehensive Assessment of Sadistic Tendencies scale (CAST; Buckels et al., in press), the Dirty Dozen Questionnaire (DD; Jonason \& Webster, 2010), and the Victim Suffering Scale (VSS), in which participants were instructed to respond to the extent to which they perceived that the aggression they inflicted upon their opponent (via the Voodoo Doll Aggression Task) resulted in their victim's actual pain and suffering. They did so across 10 ad hoc statements (for list of items see Supplemental Table 15), to which they responded along a 1 (strongly disagree) to 7 (strongly agree) scale.

\section{Procedure}

Participants completed the study online where they were randomly assigned to be either socially rejected or accepted via two same-gender students in the Cyberball paradigm (version 4.0; Williams et al., 2012). After the Cyberball task, participants 
completed the Voodoo Doll Aggression Task, with one of their Cyberball partners as the target. Participants then completed a battery of questionnaires that also included the Positive Affect During Aggression Scale (prompt: "Indicate the extent to which this statement described how you felt when you picked how many pins to stick in the doll."; e.g., Delighted, Serene), and the Short Sadistic Impulse Scale. Embedded in the battery of questionnaires were two quality check items, which instructed participants to select a specific number from a number array.

\section{Results}

\section{Descriptive Statistics}

Thirty-two participants failed at least one of the two quality checks and were subsequently excluded from all analyses. A 35-item sadism index was computed by averaging standardized responses from all 20 items of the ASP, all 10 items of the SSIS, and the 5-item Direct Physical subscale of the CAST. The Vicarious and Direct Verbal subscales of the CAST were excluded as they were not relevant to the direct and physical forms of sadistic aggression examined in this study.

Voodoo doll pin counts were not excessively skewed (skew=1.90) or leptokurtic (kurtosis $=2.71)$ but they were zero-inflated $(47.5 \%$ zeroes). Because of the extensive zero-inflation, we adopted a Poisson approach. Descriptive statistics are summarized in Supplemental Table 16. Zero-order correlations between all study variables are summarized in Table 17.

\section{Exploratory Factor Analysis - Positive Affect During Aggression Scale}

To assess the psychometric properties of the PADAS, we conducted an iterated EFA (via SAS 9.4), using direct oblimin rotation $(\delta=0)$, which allowed for the extraction 
of correlated components. Five factors were retained based on the results of a parallel analysis (Horn, 1965). An 'aggressive pleasure' subscale comprised nine items that exhibited substantial loadings onto this factor that were equal to or greater than +/-.40 (12.94\% variance explained; Supplemental Table 8). None of these items exhibited problematic cross-factor loadings (+/- .20). The second and fifth factors were labeled as the 'calmness' (6-items [2 excluded due to high cross-factor loadings]; $8.50 \%$ variance explained) and 'arousal' (4 items; $7.39 \%$ variance explained) subscales, respectively. The third (5 items [2 excluded due to high cross-factor loadings]; $7.63 \%$ variance explained) and fourth factors (4 items [2 excluded due to high cross-factor loadings]; $8.11 \%$ variance explained) did not exhibit a coherent or theoretically-sensible conceptual theme.

\section{Exploratory Factor Analysis - Victim Suffering Scale}

An identical EFA was applied to the responses to the 10 original items of the Victim Suffering Scale. Only two factors yielded items with substantial loadings (Supplemental Table 15). The two reverse-coded items loaded onto one factor that was discarded ( $1.10 \%$ variance explained), whereas the other eight items loaded onto another factor that was retained (6.64\% variance explained) and exhibited excellent internal consistency (Supplemental Table 16).

\section{Correlations with Aggressive Behavior}

Aggressive behavior on both the VDAT and HPFS were associated with greater aggression, which was observed after controlling for the dark triad (Table 7). 
Table 7. Sadism's association with aggressive behavior in Study 7. Rejection condition is coded: rejection $=1$, acceptance $=-1$. Gender is coded: male $=1$, female $=-1$.

\begin{tabular}{llllll}
\hline Model & Predictor & $B$ & $X^{2}$ & $\mathrm{df}$ & $p$ \\
\hline 1 & Sadism & 0.38 & 244.91 & 1,354 & $<.001$ \\
\cline { 2 - 6 } 2 & Gender & 0.51 & 172.79 & 1,348 & $<.001$ \\
& Sadism & 0.32 & 166.40 & 1,348 & $<.001$ \\
\cline { 2 - 6 } 3 & Rejection & 0.24 & 33.23 & 1,352 & $<.001$ \\
& Sadism & 0.42 & 223.56 & 1,352 & $<.001$ \\
& Rejection x & 0.20 & 12.27 & 1,352 & $<.001$ \\
& Sadism & & & & \\
\cline { 2 - 6 } & Rejection & 0.28 & 55.40 & 1,350 & $<.001$ \\
& Machiavellianism & 0.07 & 13.32 & 1,350 & $<.001$ \\
& Narcissism & -0.13 & 76.69 & 1,350 & $<.001$ \\
& Psychopathy & -0.07 & 7.73 & 1,350 & .005 \\
& Sadism & 0.44 & 204.04 & 1,350 & $<.001$
\end{tabular}

\section{Effect of Victim Suffering Manipulation on Aggressive Pleasure}

We tested the moderating ability of perceived victim suffering using the same PROCESS macro as detailed in Study 6; model 1). Sadism's association with aggressive pleasure experienced during aggression was magnified by perceived victim suffering, $B=0.17, t(352)=2.04, p=.043,95 \% \mathrm{Cl}=0.01,0.34$ (Figure 4). At relatively high $(+1 S D)$ levels of perceived victim suffering, sadism was positively associated with aggressive pleasure, $B=0.62, t(352)=3.89, p<.001,95 \% \mathrm{Cl}=0.30,0.93$. However, this 
effect was absent at relatively low ( $-1 S D$ ) levels of perceived victim suffering, $B=0.19$, $t(352)=0.90, p=.371,95 \% \mathrm{Cl}=-0.23,0.61$. Similar interactions were not observed with the calmness, $B=0.06, t(352)=0.63, p=.532,95 \% C l=-0.13,0.25$, or arousal, $B=0.08$, $t(352)=1.05, p=.296,95 \% \mathrm{Cl}=-0.07,0.23$, subscales of the PADAS.

Figure 4. Interactive effect from Study 7 whereby the association between sadism and the aggressive pleasure experienced during aggression is magnified by perceived victim suffering. Bands around regression lines represent $95 \%$ confidence intervals.

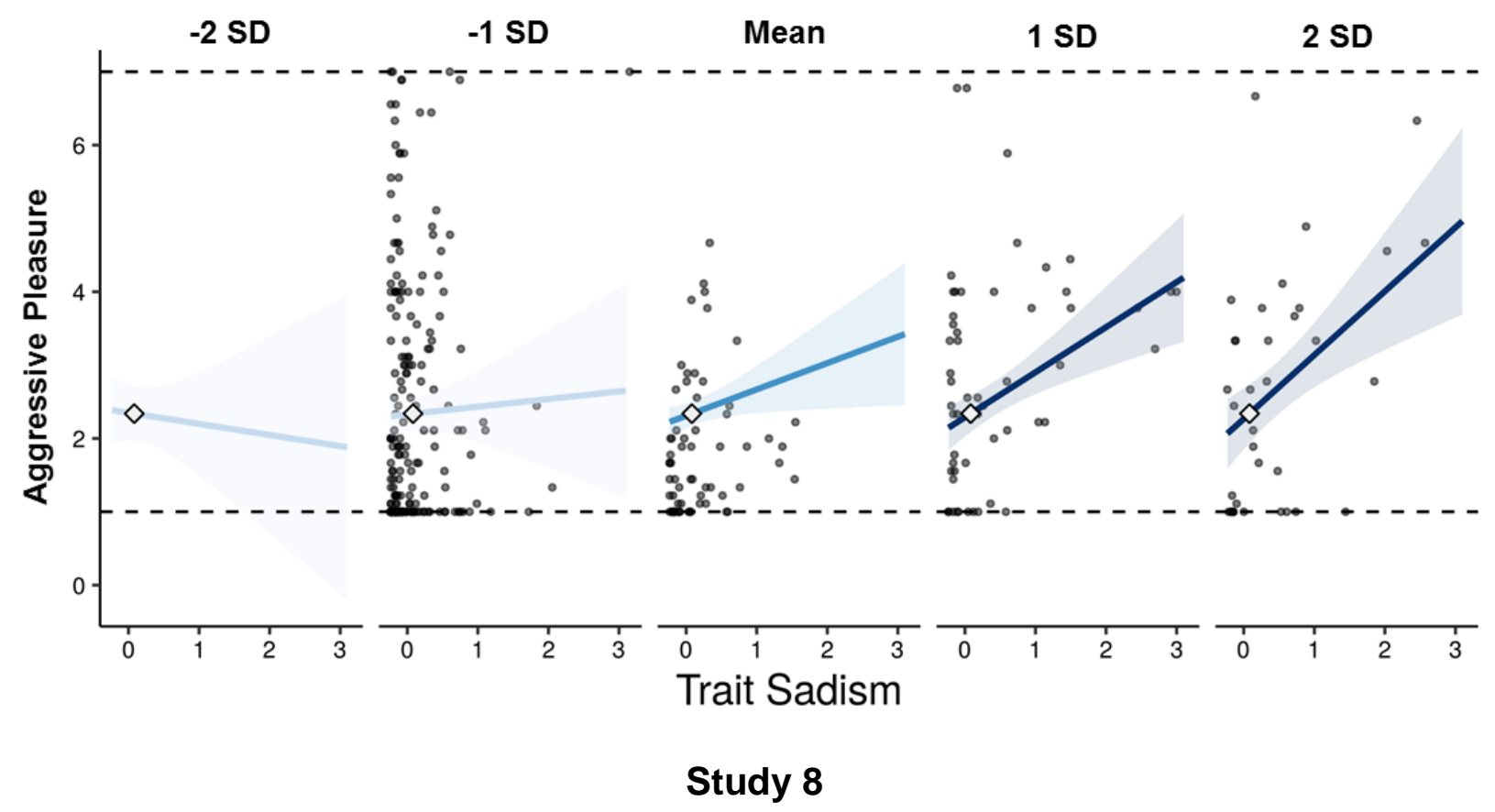

Study 8 extended beyond Study 7's correlational evidence for the critical role of victim suffering in sadistic aggression by manipulating how much participants perceived that the victim of their aggression was truly harmed by the aggressive act and then measuring the extent to which they experienced pleasure in response to the suffering. Additionally, this study employed different measures of sadism and the dark triad as control variables. 


\section{Methods}

\section{Participants}

Participants were 207 undergraduates (166 females, 41 males).

\section{Materials}

Participants completed the Short Dark Triad Scale (SD3; Jones \& Paulhus, 2014) and the Varieties of Sadistic Tendencies Scale (VAST; Paulhus \& Jones, 2015).

\section{Procedure}

Participants arrived at the laboratory where they completed the VAST, Short Sadistic Impulse Scale, and the SD3 scale. Participants then completed a 25-trial version of the Taylor Aggression Paradigm (as in Study 4). Participants were randomly assigned to hear feedback from their opponent in the aggression paradigm that either indicated they suffered due to the task's noise blasts ("Those noise blasts were unbearable! They were so loud they gave me a migraine!") or that the partner did not suffer ("Those noise blasts were nothing! Mostly, they were just annoying."). Participants completed the aggressive pleasure subscale of the Positive Affect During Aggression Scale, which was modified to assess levels of currently-felt pleasure that lingered after the aggressive act. Finally, participants completed a manipulation check (Supplemental Table 15).

\section{Results}

\section{Descriptive Statistics}

A 19-item sadism index was computed by averaging standardized responses from all 10 items of the SSIS and the 9-item Direct Sadism subscale of the VAST. We excluded the Vicarious Sadism subscale of the VAST because it was irrelevant to the 
direct and physical form of sadistic aggression measured in this study. We averaged both volume and duration levels across all 25 trials (as recommended by Chester \& Lasko, in press). Descriptive statistics are summarized in Supplemental Table 18. Zeroorder correlations between all study variables are summarized in Supplemental Table 19.

\section{Manipulation Check}

As predicted, participants in the victim suffering condition reported more victim suffering ( $M=2.51, S D=1.45)$ than did participants in the no suffering condition $(M=1.83$, $S D=1.09), t(203)=3.73, p<.001, d=0.52,95 \% C l=.25, .80$.

\section{Correlations with Aggressive Behavior}

Aggressive behavior on the TAP was not associated with sadism, $r(202)=.04$, $p=.620$, even after controlling for gender and the dark triad (Table 8).

Table 8. Sadism's association with aggressive behavior in Study 8, separated by measure. Victim pain condition is coded: victim pain=1, no pain=-1. Gender is coded: male $=1$, female $=-1$.

\begin{tabular}{lllllll}
\hline Model & Predictor & $\beta$ & $t$ & $\mathrm{df}$ & $p$ & $\Delta R^{2}$ \\
\hline 1 & Sadism & .04 & 0.50 & 202 & .620 & \\
\cline { 2 - 6 } 2 & Gender & .06 & 0.83 & 201 & .405 & \\
& Sadism & .02 & 0.25 & 201 & .802 & .00 \\
\cline { 2 - 7 } 3 & Victim Pain & .06 & 0.84 & 200 & .401 & \\
& Sadism & .04 & 0.54 & 200 & .588 & .00 \\
& Victim Pain * Sadism & -.05 & -0.65 & 200 & .519 & .00 \\
\cline { 2 - 7 } 4 & Victim Pain & .02 & 0.32 & 198 & .749 &
\end{tabular}




$\begin{array}{llllll}\text { Machiavellianism } & .06 & 0.66 & 198 & .511 & \\ \text { Narcissism } & .23 & 3.20 & 198 & .002 & \\ \text { Psychopathy } & .10 & 1.06 & 198 & .289 & \\ \text { Sadism } & -.07 & -0.81 & 198 & .422 & .00\end{array}$

\section{Effect of Victim Suffering Manipulation on Aggressive Pleasure}

Sadism's association with post-aggression pleasure was magnified by the victim suffering manipulation, $B=0.47, t(201)=2.43, p=.016,95 \% \mathrm{Cl}=0.09,0.85$ (Figure 5). Among participants in the suffering condition, sadism was unassociated with aggressive pleasure, $B=0.37, t(201)=1.56, p=.121,95 \% \mathrm{Cl}=-0.10,0.85$. Yet among participants in the no suffering condition, sadism was negatively associated with aggressive pleasure, $B=-1.51, t(201)=-2.31, p=.022,95 \% \mathrm{Cl}=-2.80,-0.22$.

Figure 5. Interactive effect from Study 8 whereby the association between sadism and the aggressive pleasure experienced during aggression is magnified by an experimental manipulation of victim suffering. Bands around regression lines represent $95 \%$ confidence intervals.

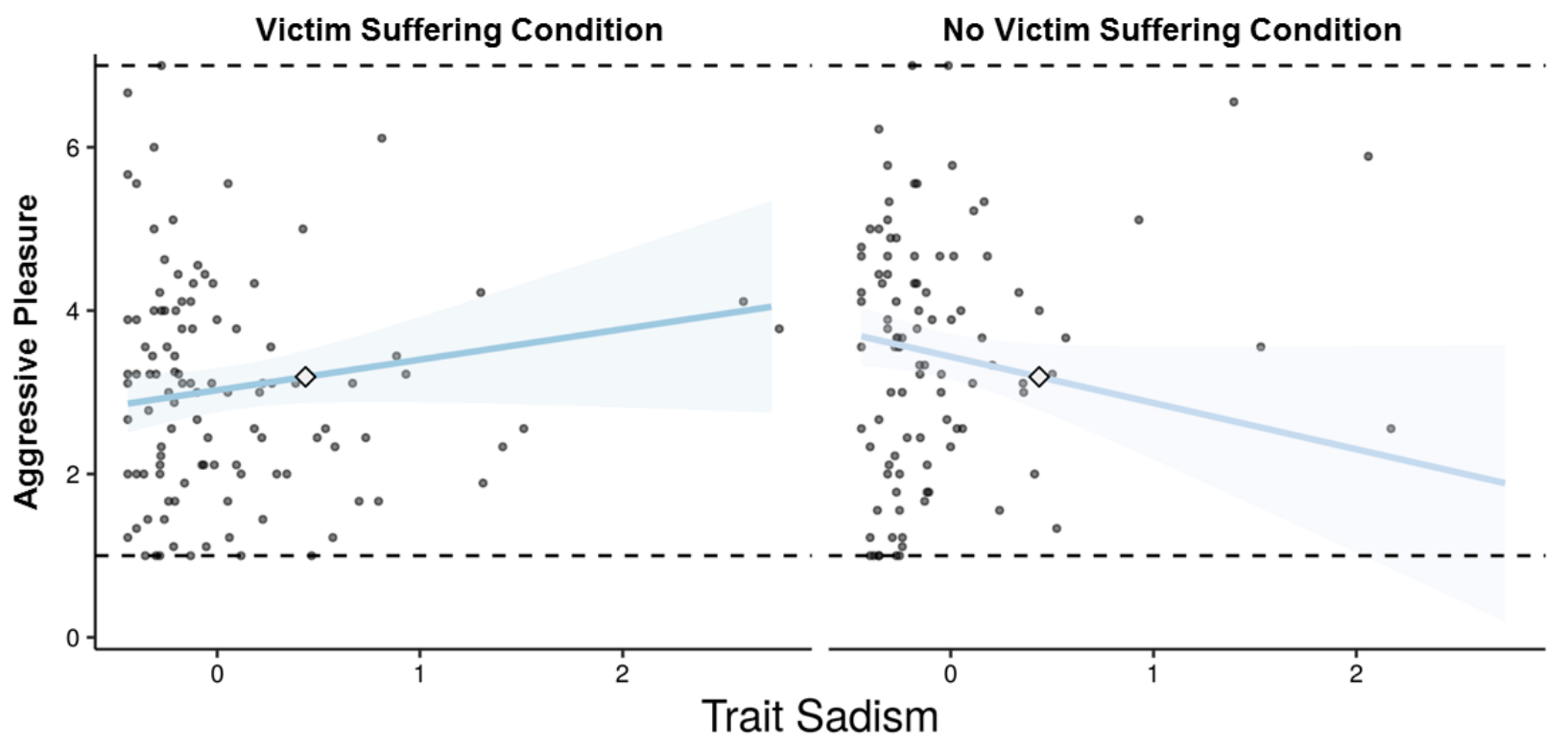




\section{Internal Meta-Analysis}

An internal, random-effects meta-analysis across the eight studies' zero-order correlations between sadism and aggressive behavior was performed using JASP v.9.0 (effect sizes [ $n=8]$, study of origin, and corresponding sample sizes are listed in Supplemental Table 20). Study 4 employed five aggression measures and in order to avoid issues with dependency between the associations, we selected the correlation between sadism and the TAP due to this measure's established validity. Using restricted maximum likelihood estimation, we observed a modest correlation between sadism and aggressive behavior, $r=.20, S E=0.04,95 \% C l=.12,29, Z=4.70, p<.001$ (Figure 6). The effects included in this internal meta-analysis exhibited significant heterogeneity, $Q(7)=20.05, p=.005$. An integrative data analysis (Curran \& Hussong, 2009) replicated this meta-analytic effect and demonstrated that this effect is curvilinear, with the sadism-aggression link becoming less positive at higher levels of sadism (Supplemental Document 1). 
Figure 6. Forest plot of sadism-aggression effects from all eight studies. Numbers on the left represent the study of origin for each effect and values on the right represent individual effect sizes and their associated $95 \%$ confidence intervals.

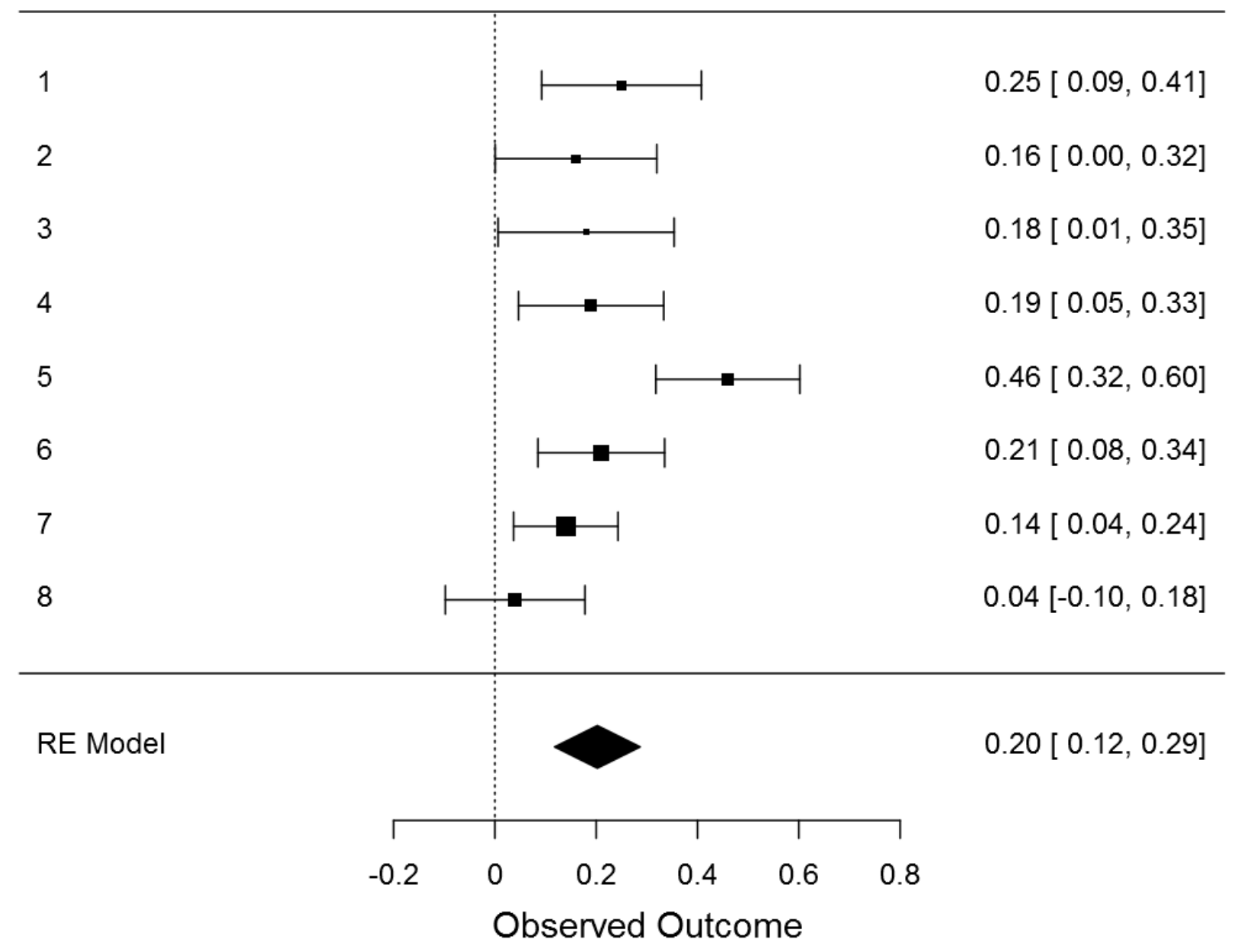

\section{Discussion}

What makes someone evil? For many, a central feature includes the tendency to cause harm to others for one's own enjoyment. These sadistic impulses do not purely reside in the gray matter of deranged killers, but can be found in the general human populace (Buckels et al., 2013). We sought to contribute to the understanding of such 'everyday sadism', testing whether these tendencies could actually be used to predict 
aggressive behavior. To do so, we examined the robustness of the sadism-aggression link across myriad aggression measures and towards innocent and provocative targets. We also tested two core tenets of the sadism construct, that sadism is associated with subjective pleasure during acts of aggression and that this pleasure is derived from the suffering inflicted on others (Baumeister, 1999: Chabrol et al., 2009).

\section{Is Sadism Linked to Aggression?}

Across eight studies, participants' self-reported sadism was positively associated with greater administrations of aversive noise blasts, painfully spicy hot sauce, gruesome images, and sharp pins administered to other people. Sadism was also linked to violent acts perpetrated in participants' real-world recent histories. These associations between sadism and aggressive behavior were robust, remaining reliable after controlling for poor self-control, impulsivity, trait aggression, and the dark triad of Machiavellianism, Narcissism, and psychopathy. This wealth of evidence replicates and extends upon previous work that highlights the discriminant validity of sadism in its role as a correlate of greater aggressive behavior (e.g., Buckels et al., 2013; Chester \& DeWall, 2017, 2018; Reidy et al., 2011). Further, sadism was linked to aggression within both males and females. Given that sadism is higher among males (Buckels et al., 2013), it was important to rule out this possibility. These results support sadism's robust (though modestly-sized) effect on aggressive behavior.

\section{Towards Whom is Sadistic Aggression Directed?}

Sadism was associated with both retaliatory aggression towards provocateurs and also towards innocent targets. In two studies, sadistic aggression was more strongly directed at innocent individuals. These findings replicate previous work linking 
sadism to aggression against innocent individuals (Buckels et al., 2013), provide a novel extension by linking sadism to retaliatory forms of aggression, and suggest that sadistic forms of aggression are largely numb to situational inputs that normally magnify aggression. The inability of these provocations to amplify sadists' aggression suggests a different motivation than revenge, and may be rooted in the anticipated affect surrounding sadistic acts.

\section{Is the Aggressive Behavior of Sadists Linked to the Experience of Pleasure?}

Although we initially expected that sadists would experience greater positive affect after an aggressive act (as in Buckels et al., 2013), we routinely observed that sadism was unassociated with such post-aggression positive affect. This discrepancy may be due to the fact that the targets of aggression in the studies performed by Buckels and colleagues (2013) were pill bugs and not humans. Conversely, sadism was most often associated with greater negative affect after aggression. This association was not simply due to sadists' general tendency to experience greater negative affect, as we statistically controlled for baseline affect. It appears that, while sadists appear to be more aggressive, these aggressive acts seem to have a detrimental impact on their mood. In line with recent research on aggression's perceived emotion-regulating qualities (Chester \& DeWall, 2017), sadists may perceive as aggression an effective means to improve their mood, despite its contrary results.

We developed a new self-report measure of aggressive pleasure, which demonstrated that sadism was associated with greater pleasure during the aggressive act. Further, such aggressive pleasure accounted for a significant portion of the effect of sadism on aggression. Sadism may thus be reinforced by experiences of aggressive 
pleasure and this reinforcement may serve as a proximate mechanism by which aggressive and sadistic traits and tendencies are formed and reinforced over time (Chester, Lynam, Milich, \& DeWall, 2018). These findings fit within the growing literature that establishes positively-valenced affective states as a potent motivator of aggression (Chester, 2017). The findings are also in line with predictions from the General Aggression Model in terms of how personality input variables can increase the likelihood of aggression through affect, appraisal and decision-making processes, and feedback loops (Anderson \& Bushman, 2002; DeWall et al., 2011).

\section{Do Sadists Derive Pleasure from Others' Suffering?}

By measuring and manipulating how much the victims of participants' aggression were perceived to experience actual suffering, we established that aggressive pleasure is contingent upon the perceived suffering of sadists' victims. This core feature of sadism has been theorized (Baumeister, 1999: Chabrol et al., 2009), but our studies offer the first definitive evidence. Typically, others' suffering is automatically met with empathic concern and shared distress (Preston \& De Waal, 2002), yet sadists display an opposing process in which others' pain is transmuted into their pleasure. More work is needed to understand the precise psychological and biological mechanisms that allow others' pain to be experienced as pleasant.

\section{Limitations and Future Directions}

Our assessments of sadism were exclusively explicit and obtained via self-report. Sadism is a socially-undesirable trait. As such, participants may have under-reported their sadism. Future research may use implicit measures of sadism (Reidy et al., 2011) to outflank this limitation. However, under-reporting is only problematic if certain types of 
individuals differentially under-report sadism, or if certain methodological techniques or contexts elicit differential responding. We observed no evidence of differential underreporting in our data.

Sadism tends to be greater among males than females (Buckels et al., 2013), and our studies were not conducted to explicitly take gender effects into account. Entering gender as a covariate did not fundamentally alter sadism's link to aggression across the majority of our studies, suggesting that our effects were not artifacts of males' greater sadism. However, future research is needed that treats gender as a variable of interest and not a nuisance factor.

Another effect of the self-report approach we took to measuring sadism was that our findings were purely correlational. As such, we cannot be sure of the directionality of our effects or if other variables artificially created them. Such correlations do not allow for the establishment of a temporal or causal sequences of variables and violate many of the assumptions of mediation modeling (see Giner-Sorolla, 2016). Experimental manipulations that increase sadistic states should be developed to allow for causal inferences and directional statements about the sadism-aggression link. Further, longitudinal work that is interrogated with cross-lagged analyses would allow for directional inferences.

In addition to these assessment issues, our findings were obtained with undergraduate and Mechanical Turk participants who are unlikely to exhibit the violent and belligerent behavior of forensically- or clinically-aggressive individuals or the larger proportion of the global human population for that matter (Henrich, Heine, \& Norenzayan, 2010). Undergraduate and Mechanical Turk populations possess 
characteristics (e.g., wealth, education-level, societal structure) that are not replicated in most of the world. As such, it is crucial for future research to replicate our effects with diverse populations that better approximate the true range of aggressive tendencies in the real world. We also frequently used experimentally-manipulated variables as covariates in many of our analyses. The appropriateness of including experimentallymanipulated variables, which should already be equivalent across most demographic and trait domains, is debatable and readers should use caution when interpreting the results of such covariate analyses.

\section{Conclusion}

What people enjoy varies wildly. Some people enjoy hurting others. We found that these tendencies are not confined to people's heads and bleed into their actions as well. Where people fall along the sadistic spectrum seems to predict how aggressively they act towards others and the pain they inflict promotes a fleeting sense of pleasure that is soon replaced by affective discomfort. It is our hope that shining light on such dark features of personality leads to greater understanding and interventions that manage to break the link between personal pleasure and others' suffering. 


\section{References}

Anderson, C. A., \& Bushman, B. J. (1997). External validity of "trivial" experiments: The case of laboratory aggression. Review of General Psychology, 1, 19-41.

Anderson, C. A., \& Bushman, B. J. (2002). Human aggression. Annual Review of Psychology, 53, 27-51.

Baughman, H. M., Dearing, S., Giammarco, E., \& Vernon, P. A. (2012). Relationships between bullying behaviours and the Dark Triad: A study with adults. Personality and Individual Differences, 52, 571-575.

Baumeister R. F. (1997). Evil: inside human violence and cruelty. New York, NY: W.H. Freeman.

Berkowitz, L. (1989). Affective aggression: The role of stress, pain, and negative affect. In R. G. Geen \& E. Donnerstein (Eds.), Human aggression: theories, research, and implications for social policy (pp. 49-72). San Diego, CA: Academic Press.

Buckels, E. E., Jones, D. N., \& Paulhus, D. L. (2013). Behavioral confirmation of everyday sadism. Psychological Science, 24, 2201-2209.

Buckels, E. E., Trapnell, P. D., Andjelovic, T., \& Paulhus, D. L. (in press). Internet trolling and everyday sadism: Parallel effects on pain perception and moral judgment. Journal of Personality.

Buckels, E. E., Trapnell, P. D., \& Paulhus, D. L. (2014). Trolls just want to have fun. Personality and individual Differences, 67, 97-102.

Bushman, B. J., \& Baumeister, R. F. (1998). Threatened egotism, narcissism, selfesteem, and direct and displaced aggression: Does self-love or self-hate lead to violence? Journal of Personality and Social Psychology, 75, 219-229. 
Bushman, B. J., Baumeister, R. F., \& Phillips, C. M. (2001). Do people aggress to improve their mood? Catharsis beliefs, affect regulation opportunity, and aggressive responding. Journal of Personality and Social Psychology, 81, 17-32.

Chabrol, H., Van Leeuwen, N., Rodgers, R., \& Séjourné, N. (2009). Contributions of psychopathic, narcissistic, Machiavellian, and sadistic personality traits to juvenile delinquency. Personality and Individual Differences, 47, 734-739.

Chester, D. S. (2017). The role of positive affect in aggression. Current Directions in Psychological Science, 26, 366-370.

Chester, D. S. \& DeWall, C. N. (2016). The pleasure of revenge: Retaliatory aggression arises from a neural imbalance towards reward. Social Cognitive and Affective Neuroscience, 11, 1173-1182.

Chester, D. S. \& DeWall, C. N. (2017). Combating the sting of rejection with the pleasure of revenge: A new look at how emotion shapes aggression. Journal of Personality and Social Psychology, 112, 413-430.

Chester, D. S. \& DeWall, C. N. (2018). Personality correlates of revenge-seeking: Multidimensional links to physical aggression, impulsivity, and aggressive pleasure. Aggressive Behavior, 44, 235-245.

Chester, D. S., DeWall, C. N., Derefinko, K. J., Estus, S., Peters, J. R., Lynam, D. R., \& Jiang, Y. (2015). Monoamine oxidase A (MAOA) genotype predicts greater aggression through impulsive reactivity to negative affect. Behavioural Brain Research, 283, 97-101.

Chester, D. S., DeWall, C. N., Derefinko, K. J., Estus, S., Lynam, D. R., Peters, J. R., \& Jiang, Y. (2016). Looking for reward in all the wrong places: Dopamine receptor 
gene polymorphisms indirectly affect aggression through sensation-seeking. Social Neuroscience, 11, 487-494.

Chester, D. S. \& Lasko, E. N. (in press). Validating a standardized approach to the Taylor Aggression Paradigm. Social Psychological and Personality Science.

Chester, D. S., Lynam, D. R., Milich, R., \& DeWall, C. N. (2018). Neural mechanisms of the rejection-aggression link. Social Cognitive and Affective Neuroscience, 13, $501-512$

Curran, P. J., \& Hussong, A. M. (2009). Integrative data analysis: the simultaneous analysis of multiple data sets. Psychological Methods, 14, 81-100.

Curran, S. L., Andrykowski, M. A., \& Studts, J. L. (1995). Short form of the Profile of Mood States (POMS-SF): Psychometric information. Psychological Assessment, 7, 80-83.

Denson, T. F., DeWall, C. N., \& Finkel, E. J. (2012). Self-control and aggression. Current Directions in Psychological Science, 21, 20-25.

DeWall, C. N., Anderson, C. A., \& Bushman, B. J. (2011). The General Aggression Model: Theoretical extensions to violence. Psychology of Violence, 1, 245-258.

DeWall, C. N., Finkel, E. J., Lambert, N. M., Slotter, E. B., Bodenhausen, G. V., Pond, R. S., ... Fincham, F. D. (2013). The voodoo doll task: Introducing and validating a novel method for studying aggressive inclinations. Aggressive Behavior, 39, 419-439.

DeWall, C. N., Twenge, J. M., Bushman, B., Im, C., \& Williams, K. (2010). A little acceptance goes a long way: applying social impact theory to the rejectionaggression link. Social Psychological and Personality Science, 1, 168-174. 
Eadeh, F. R., Peak, S. A., \& Lambert, A. J. (2017). The bittersweet taste of revenge: On the negative and positive consequences of retaliation. Journal of Experimental Social Psychology, 68, 27-39.Furnham, A., Richards, S. C., \& Paulhus, D. L. (2013). The Dark Triad of personality: A 10 year review. Social and Personality Psychology Compass, 7, 199-216.

Giancola, P., \& Chermack, S. (1998). Construct validity of laboratory aggression paradigms: A response to Tedeschi and Quigley (1996). Aggression and Violent Behavior, 3, 237-253.

Giner-Sorolla, R. (2016). Approaching a fair deal for significance and other concerns. Journal of Experimental Social Psychology, 65, 1-6.

Gollwitzer, M., \& Bushman, B. J. (2012). Do Victims of Injustice Punish to Improve Their Mood? Social Psychological and Personality Science, 3, 572-580.HarmonJones, C., Bastian, B., \& Harmon-Jones, E. (2016). The Discrete Emotions Questionnaire: A New Tool for Measuring State Self-Reported Emotions. PLoS ONE, 11, no pagination specified.

Hayes, A. F. (2012). PROCESS: A versatile computational tool for observed variable mediation, moderation, and conditional process modeling. Retrieved from http://www.afhayes.com/public/process2012.pdf

Henrich, J., Heine, S. J., \& Norenzayan, A. (2010). The weirdest people in the world?. Behavioral and Brain Sciences, 33, 61-83.

Horn, J. L. (1965). A rationale and test for the number of factors in factor analysis. Psychometrika, 30, 179-185. 
Jonason, P. K., \& Webster, G. D. (2010). The dirty dozen: A concise measure of the dark triad. Psychological Assessment, 22, 420.

Jonason, P. K., Zeigler-Hill, V., \& Okan, C. (2017). Good v. evil: Predicting sinning with dark personality traits and moral foundations. Personality and Individual Differences, 104, 180-185.

Jones, D. N., \& Paulhus, D. L. (2014). Introducing the short dark triad (SD3) a brief measure of dark personality traits. Assessment, 21, 28-41.

Kirkpatrick, L. A., Waugh, C. E., Valencia, A., \& Webster, G. D. (2002). The functional domain specificity of self-esteem and the differential prediction of aggression. Journal of Personality and Social Psychology, 82, 756-767.

Krueger, R. B. (2010). The DSM diagnostic criteria for sexual sadism. Archives of Sexual Behavior, 39, 325-345.

Levenson, M . R., Kiehl, K. A., \& Fitzpatrick, C. M. (1995). Assessing psychopathic attributes in a noninstitutionalized population. Journal of Personality and Social Psychology, 68, 151-158.

Lieberman, J. D., Solomon, S., Greenberg, J., \& McGregor, H. A. (1999). A hot new way to measure aggression: Hot sauce allocation. Aggressive Behavior, 25, 331-348.

March, E., Grieve, R., Marrington, J., \& Jonason, P. K. (2017). Trolling on Tinder®(and other dating apps): Examining the role of the Dark Tetrad and impulsivity. Personality and Individual Differences, 110, 139-143.

Martens, A., Kosloff, S., Greenberg, J., Landau, M. J., \& Schmader, T. (2007). Killing begets killing: Evidence from a bug-killing paradigm that initial killing fuels subsequent killing. Personality and Social Psychology Bulletin, 33, 1251-1264. 
Miller, J. D., \& Lynam, D. R. (2006). Reactive and proactive aggression: Similarities and differences. Personality and Individual Differences, 41, 1469-1480.

O’Meara, A., Davies, J., \& Hammond, S. (2011). The psychometric properties and utility of the Short Sadistic Impulse Scale (SSIS). Psychological Assessment, 23, 523531.

Paulhus, D. L. (2014). Toward a taxonomy of dark personalities. Current Directions in Psychological Science, 23, 421-426.

Paulhus, D. L., Curtis, S. R., \& Jones, D. N. (2018). Aggression as a trait: the Dark Tetrad alternative. Current Opinion in Psychology, 19, 88-92.

Paulhus, D. L., \& Jones, D. N. (2015). Measuring dark personalities via questionnaire. In G. J. Boyle, D. H. Saklofske \& G. Matthews (Eds.), Measures of personality and social psychological constructs (pp. 562-594). San Diego, CA: Academic Press.

Paulhus, D. L., \& Williams, K. M. (2002). The dark triad of personality: Narcissism, Machiavellianism, and psychopathy. Journal of Research in Personality, 36, 556563.

Pedersen, W. C., Gonzales, C., \& Miller, N. (2000). The moderating effect of trivial triggering provocation on displaced aggression. Journal of Personality and Social Psychology, 78, 913-927.Plouffe, R. A., Saklofske, D. H., \& Smith, M. M. (2017). The Assessment of Sadistic Personality: Preliminary psychometric evidence for a new measure. Personality and Individual Differences, 104, 166-171. 
Porter, S., \& Woodworth, M. (2006). Psychopathy and aggression. In CJ Patrick (Ed.), Handbook of psychopathy (pp. 481-494). New York, NY: Guilford Press; 2006.

Preston, S. D., \& De Waal, F. B. (2002). Empathy: Its ultimate and proximate bases. Behavioral and brain sciences, 25, 1-20.

Raine, A., Dodge, K., Loeber, R., Gatzke-Kopp, L., Lynam, D., Reynolds, C., ... \& Liu, J. (2006). The reactive-proactive aggression questionnaire: Differential correlates of reactive and proactive aggression in adolescent boys. Aggressive Behavior, 32, 159-171.

Reidy, D. E., Zeichner, A., \& Martinez, M. A. (2008). Effects of psychopathy traits on unprovoked aggression. Aggressive Behavior, 34, 319-328.

Reidy, D. E., Zeichner, A., Miller, J. D., \& Martinez, M. A. (2007). Psychopathy and aggression: Examining the role of psychopathy factors in predicting laboratory aggression under hostile and instrumental conditions. Journal of Research in Personality, 41, 1244-1251.

Reidy, D. E., Zeichner, A., \& Seibert, L. A. (2011). Unprovoked aggression: Effects of psychopathic traits and sadism. Journal of Personality, 79, 75-100.

Richard, F. D., Bond Jr, C. F., \& Stokes-Zoota, J. J. (2003). One hundred years of social psychology quantitatively described. Review of General Psychology, 7, 331-363.

Russell, T. D., \& King, A. R. (2016). Anxious, hostile, and sadistic: Maternal attachment and everyday sadism predict hostile masculine beliefs and male sexual violence. Personality and Individual Differences, 99, 340-345. 
Tangney, J. P., Baumeister, R. F., \& Boone, A. L. (2004). High Self-Control Predicts Good Adjustment, Less Pathology, Better Grades, and Interpersonal Success. Journal of Personality, 72, 271-324.

Taylor, S. (1967). Aggressive behavior and physiological arousal as a function of provocation and the tendency to inhibit aggression. Journal of Personality, 35, 297-310.Watson, D., Clark, L. A., \& Tellegen, A. (1988). Development and validation of brief measures of positive and negative affect: The PANAS scales. Journal o Personality and Social Psychology, 54, 1063-1070.

Webster, G. D., DeWall, C. N., Pond, R. S., Deckman, T., Jonason, P. K., Le, B. M., ... \& Smith, C. V. (2014). The brief aggression questionnaire: Psychometric and behavioral evidence for an efficient measure of trait aggression. Aggressive Behavior, 40, 120-139.

Webster, G. D., Gesselman, A. N., Crysel, L. C., Brunell, A. B., Jonason, P. K., Hadden, B. W., \& Smith, C. V. (2016). An actor-partner interdependence model of the Dark Triad and aggression in couples: Relationship duration moderates the link between psychopathy and argumentativeness. Personality and Individual Differences, 101, 196-207.

Webster, G. D., \& Kirkpatrick, L. A. (2006). Behavioral and self-reported aggression as a function of domain-specific self-esteem. Aggressive Behavior, 32, 1727.Whiteside, S. P., \& Lynam, D. R. (2001). The Five Factor Model and impulsivity: using a structural model of personality to understand impulsivity. Personality and Individual Differences, 30, 669-689. 
Whiteside, S. P., Lynam, D. R., Miller, J. D., \& Reynolds, S. K. (2005). Validation of the UPPS impulsive behaviour scale: A four-factor model of impulsivity. European Journal of Personality, 19, 559-574.

Williams, K. D. (2009). Ostracism: A temporal need-threat model. In Mark P. Zanna (Ed.), Advances in experimental social psychology (pp. 275-314). Cambridge, MA: Academic Press.

Williams, K. D., Cheung, C. T, K., \& Choi, W. (2000). Cyberostracism: Effects of being ignored over the Internet. Journal of Personality and Social Psychology, 79, 748762.

Williams, K.S., Yeager, D.S., Cheung, C.K.T., \& Choi, W. (2012). Cyberball (version 4.0) [Software]. Available from https://cyberball.wikispaces.com. 


\section{Supplemental Document 1}

\section{Integrative Data Analysis}

We performed integrative data analyses by combining the datasets from all eight studies, standardizing sadism and aggression scores within-study. Because Study 4 employed five aggression measures, we standardized each of them, averaged them together, and then standardized this aggression index to enter into the integrative data analysis. The analysis took the form of a multilevel linear model in SAS v.9.4, using maximum likelihood estimation, specifying the study of origin and intercepts as random, and modeling the following sources of variance: participant (level 1), study (level 2;). Sadism exhibited significant linear, $\beta=0.22, S E=0.03,95 \% C l=0.17,0.27, t(1,515)=8.51$, $p<.001$, and curvilinear, $\beta=-0.19, S E=0.07,95 \% C l=-0.05,-0.33, t(918)=-2.68, p=.008$ (Supplemental Figure 1), associations with aggression across all eight studies. 
Supplemental Figure 1. Curvilinear association between sadism and aggressive behavior across all eight studies. Bands around the regression slope depict $95 \%$ confidence intervals.

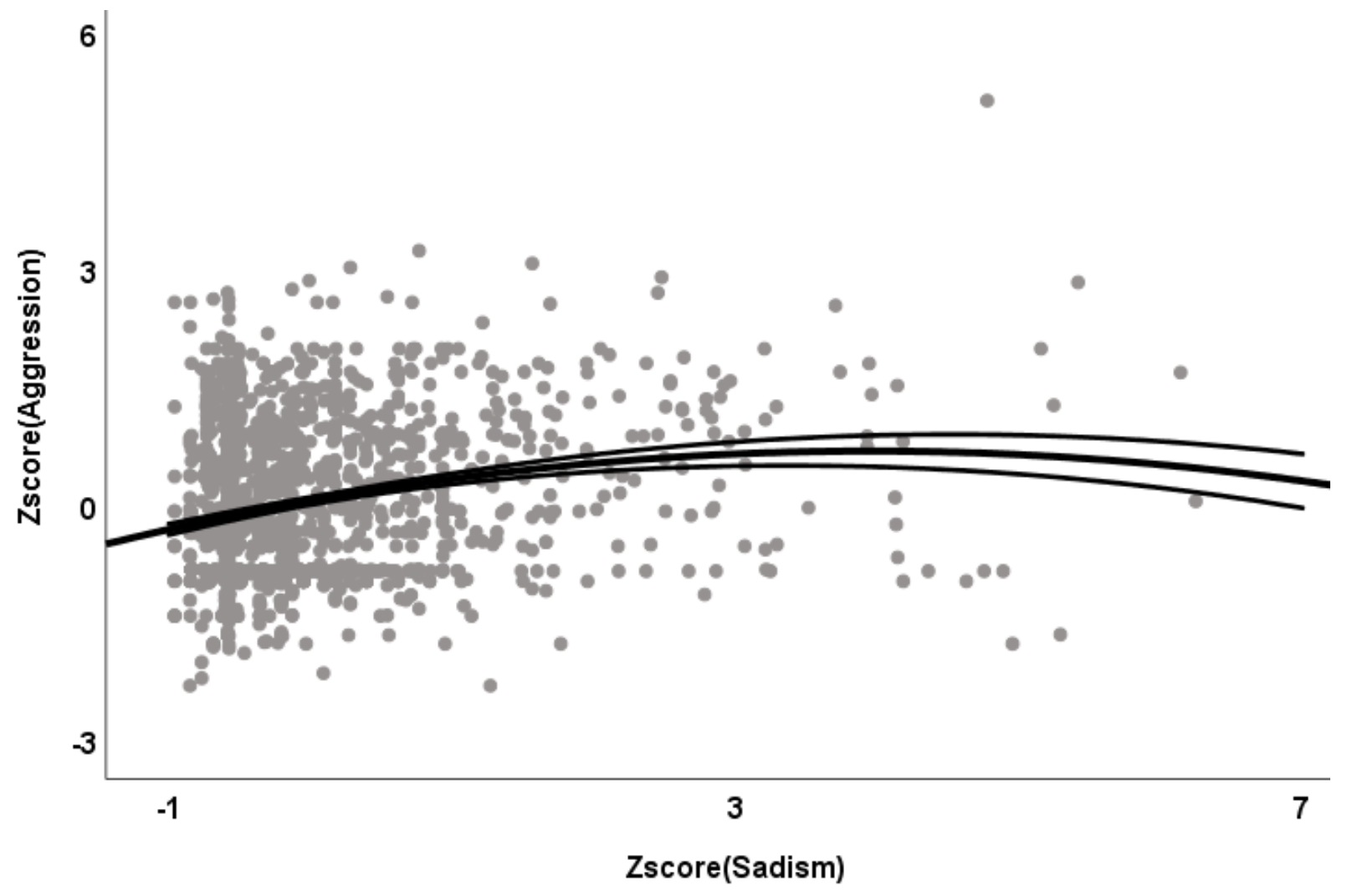


Supplemental Table 1. Descriptive statistics and internal scale consistencies for key variables from Study 1. NTS = Need Threat Scale, LSRP = Levenson Self-Report Psychopathy Scale, SSIS = Short Sadistic Impulse Scale, UPPSP = UPPS-P Impulsivity Scale. 'Pre' and 'Post' refer to before and after participants completed the aggression measure, respectively.

\begin{tabular}{lllllll}
\hline Measure & $M$ & $S D$ & Observed & Observed & $\alpha$ & Missing Data \\
& & & Minimum & Maximum & & $N$ \\
\hline Brief Self-Control Scale & 3.39 & 0.67 & 1.69 & 5.00 & .84 & 9 \\
NTS - Negative Affect (Pre) & 1.38 & 0.57 & 1.00 & 3.33 & .73 & 4 \\
NTS - Positive Affect (Pre) & 3.76 & 0.70 & 2.00 & 5.00 & .81 & 4 \\
NTS - Negative Affect (Post) & 1.68 & 0.77 & 1.00 & 4.00 & .68 & 28 \\
NTS - Positive Affect (Post) & 3.02 & 0.96 & 1.00 & 5.00 & .85 & 28 \\
LSRP - Primary & 28.70 & 8.74 & 4.00 & 56.00 & .81 & 17 \\
LSRP - Secondary & 18.00 & 5.11 & 2.00 & 35.00 & .74 & 16 \\
SSIS (10 items) & 1.48 & 0.32 & 1.00 & 3.30 & .55 & 12 \\
SSIS (9 items) & 1.17 & 0.29 & 1.00 & 3.00 & .73 & 12 \\
Taylor Aggression Paradigm & 3.80 & 2.25 & 0.00 & 10.00 & .98 & 7
\end{tabular}




\begin{tabular}{lllllll} 
UPPSP - Lack of Perseverance & 1.89 & 0.47 & 1.00 & 3.60 & .81 & 4 \\
UPPSP - Lack of Premeditation & 2.01 & 0.48 & 1.00 & 3.36 & .83 & 4 \\
UPPSP - Negative Urgency & 2.05 & 0.60 & 1.08 & 3.92 & .87 & 4 \\
UPPSP - Positive Urgency & 1.70 & 0.61 & 1.00 & 3.64 & .93 & 4 \\
UPPSP - Sensation-Seeking & 2.85 & 0.62 & 1.33 & 4.00 & .85 & 4 \\
\hline
\end{tabular}


Supplemental Table 2. Zero-order correlations between key variables from Study 1. BSCS = Brief Self-Control Scale, NTS = Need Threat Scale, LSRP = Levenson Self-Report Psychopathy Scale, SSIS = Short Sadistic Impulse Scale (9 items), TAP = Taylor Aggression Paradigm, UPPSP = UPPS-P Impulsivity Scale. 'Pre' and 'Post' refer to before and after participants completed the aggression measure, respectively. Gender is coded: male $=1$, female $=-1 .{ }^{\star} p<.05,{ }^{\star \star} p<.01$

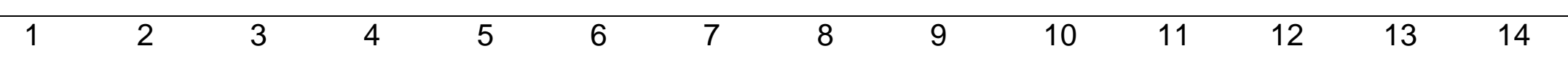

\section{BSCS}

2. Gender $\quad-.17^{*}$

3. NTS - Negative $\quad-.13 \quad-.00$

Affect (Pre)

4. NTS - Positive $\quad .14 \quad-.04 \quad-.48^{* *}$

Affect (Pre)

5. NTS - Negative $\quad-.22^{*} \quad .05 \quad .28^{* *} \quad-.05$

Affect (Post) 
6. NTS - Positive $\quad \begin{array}{lllll}-.00 & .02 & -.13 & .33^{* *} & -.44^{* *}\end{array}$

Affect (Post)

7. LSRP - Primary $\begin{array}{lllllll}-.36^{* *} & .17^{*} & .10 & -.08 & .19^{*} & -.02\end{array}$

8. LSRP - $\quad-.63^{* *} \quad .07 \quad .23^{* *} \quad-.24^{\star *} \quad .20^{*} \quad-.05 \quad .57^{\star *}$

Secondary

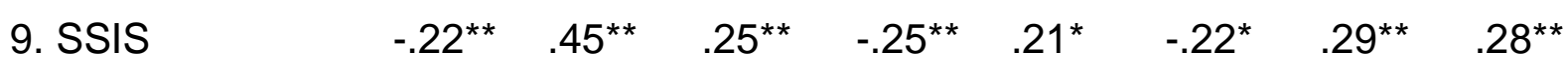

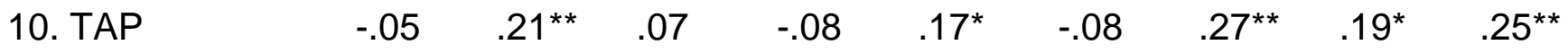

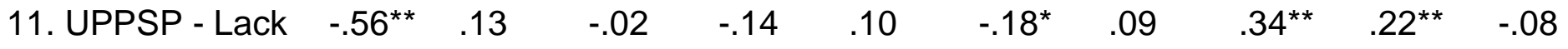

of Perseverance

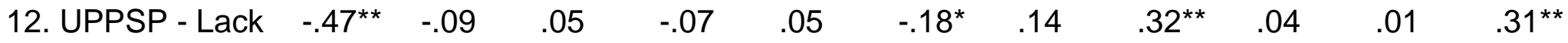

of Premeditation

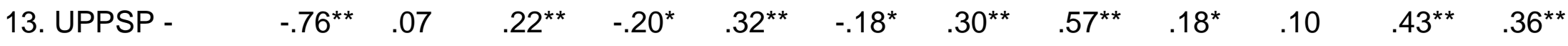

Negative Urgency 


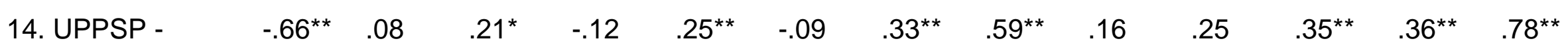

Positive Urgency

$\begin{array}{llllllllllllllllllll}\text { 15. UPPSP - } & -.31^{* *} & .09 & .07 & .12 & .11 & .08 & .25^{* *} & .34^{* *} & .09 & .04 & .08 & .27^{* *} & .20^{*} & .29^{* *}\end{array}$ Sensation-

Seeking 
Supplemental Table 3. Descriptive statistics and internal scale consistencies for key variables from Study 2.

HSAT = Hot Sauce Aggression Task, NTS = Need Threat Scale, LSRP = Levenson Self-Report Psychopathy Scale, SSIS = Short Sadistic Impulse Scale. 'Pre' and 'Post' refer to before and after participants completed the aggression measure, respectively.

\begin{tabular}{|c|c|c|c|c|c|c|}
\hline Measure & $M$ & $S D$ & $\begin{array}{l}\text { Observed } \\
\text { Minimum }\end{array}$ & $\begin{array}{l}\text { Observed } \\
\text { Maximum }\end{array}$ & $\alpha$ & $\begin{array}{l}\text { Missing Data } \\
N\end{array}$ \\
\hline HSAT (Log Transformed) & 0.97 & 0.11 & 0.85 & 1.49 & $\mathrm{n} / \mathrm{a}$ & 0 \\
\hline NTS - Negative Affect (Pre) & 2.17 & 1.36 & 1.00 & 7.00 & .84 & 0 \\
\hline NTS - Positive Affect (Pre) & 4.45 & 1.51 & 1.00 & 7.00 & .90 & 0 \\
\hline NTS - Negative Affect (Post) & 1.71 & 1.00 & 1.00 & 7.00 & .81 & 1 \\
\hline NTS - Positive Affect (Post) & 5.20 & 1.36 & 1.00 & 7.00 & .91 & 1 \\
\hline LSRP - Primary & 29.71 & 6.81 & 16.00 & 53.00 & .84 & 0 \\
\hline LSRP - Secondary & 19.68 & 3.66 & 12.00 & 29.00 & .59 & 0 \\
\hline SSIS (10 items) & 1.42 & 0.52 & 1.00 & 4.10 & .65 & 0 \\
\hline SSIS (9 items) & 1.29 & 0.50 & 1.00 & 4.33 & .79 & 0 \\
\hline
\end{tabular}


Supplemental Table 4. Zero-order correlations between key variables from Study 2. HSAT = Hot Sauce Aggression Task, NTS = Need Threat Scale, LSRP = Levenson Self-Report Psychopathy Scale. 'Pre' and 'Post' refer to before and after participants completed the aggression measure, respectively. Gender is coded: male $=1$, female $=-1 .{ }^{\star} p<.05,{ }^{\star \star} p$ $<.01,{ }^{\star * \star} p<.001$

23

4

5

6

8

1. Gender

2. HSAT (Log Transformed) $.21^{*}$

3. NTS - Negative Affect (Pre) - $-.11 \quad-.01$

4. NTS - Positive Affect (Pre) $\quad .06 \quad .05 \quad-.61^{\star \star *}$

5. NTS - Negative Affect (Post) $\quad-.14 \quad .02 \quad .38^{\star \star \star} \quad-.34^{\star \star *}$

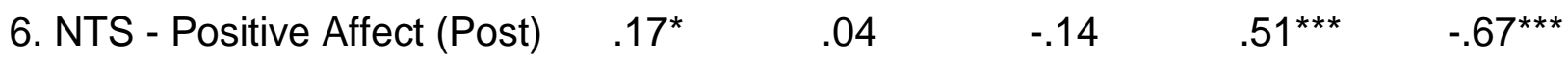

7. LSRP - Primary

$.25^{\star *} \quad .18^{*}$

$-.09$

$-.06$

$-.04$

.00

8. LSRP - Secondary

$.02 \quad .17^{*} \quad .10$

$-.15$

.15

$-.14$

$.39^{\star \star *}$

9. Short Sadistic Impulse Scale

.16

.08

.02

$.21^{* *}$

$-.05$

$.40^{\star \star *} \quad .35^{\star \star \star}$ 
Supplemental Table 5. Descriptive statistics and internal scale consistencies for key variables from Study 3 . NTS

= Need Threat Scale. 'Pre' and 'Post' refer to before and after participants completed the aggression measure, respectively.

\begin{tabular}{|c|c|c|c|c|c|c|}
\hline Measure & $M$ & $S D$ & $\begin{array}{l}\text { Observed } \\
\text { Minimum }\end{array}$ & $\begin{array}{l}\text { Observed } \\
\text { Maximum }\end{array}$ & $\alpha$ & Missing Data $N$ \\
\hline Gruesome Images & 3.21 & 2.25 & 0.00 & 9.00 & $\mathrm{n} / \mathrm{a}$ & 0 \\
\hline NTS - Negative Affect (Pre) & 2.19 & 1.02 & 1.00 & 5.00 & .86 & 1 \\
\hline NTS - Positive Affect (Pre) & 2.93 & 0.93 & 1.00 & 5.00 & .87 & 1 \\
\hline NTS - Negative Affect (Post) & 3.27 & 0.91 & 1.33 & 5.00 & .86 & 5 \\
\hline NTS - Positive Affect (Post) & 2.01 & 0.93 & 1.00 & 4.67 & .89 & 5 \\
\hline Short Sadistic Impulse Scale & 1.86 & 0.89 & 1.00 & 5.60 & .85 & 1 \\
\hline
\end{tabular}


Supplemental Table 6. Zero-order correlations between key variables from Study 3. NTS = Need Threat Scale. 'Pre' and 'Post' refer to before and after participants completed the aggression measure, respectively. Gender is coded: male $=1$, female $=-1 .{ }^{*} p<.05,{ }^{\star \star} p<$ $.01,{ }^{* \star *} p<.001$

1 .06 3. NTS - Negative Affect (Pre) $\quad .09 \quad-.00$

4. NTS - Positive Affect (Pre) $\quad .09 \quad .08$

5. NTS - Negative Affect (Post) $\quad .06 \quad .08$

6. NTS - Positive Affect (Post) $\quad .03 \quad-.03$

7. Short Sadistic Impulse Scale $\quad .17$

1. Gender

2. Gruesome Images

.03

2

3

4

$.08-.26^{\star *}$

$.08 \quad .53^{* * *}-.08$

$-.15$

$.46^{\star \star *}$

$-.38^{* * *}$

$.18^{*} \quad .08$

$-.14$

$.24^{* *}$

$-.16$ 
Supplemental Table 7. Item text for the Positive Affect During Aggression Scale, taken from the Need Threat Affect Subscales (NTAS), Positive Affect Negative Affect Schedule (PANAS), Profile of Mood States (POMS), Discrete Emotions Questionnaire (DEQ), and generated by the authors (ADHOC). 'Retained in final 9-item Aggressive Pleasure subscale.

\begin{tabular}{ll}
\hline Original Scale & $\begin{array}{l}\text { Indicate the extent to which this statement described how you felt } \\
\text { when your opponent received the noise blasts that you picked in } \\
\text { the competitive reaction-time task... }\end{array}$ \\
\hline PANAS & Active \\
PANAS & Alert \\
DEQ & Anticipation \\
ADHOC & At peace \\
PANAS & Attentive \\
ADHOC & Blessed \\
DEQ & Calm \\
ADHOC & Carefree \\
ADHOC & Delighted
\end{tabular}




$\begin{array}{ll}\text { PANAS } & \text { Determined } \\ \text { ADHOC } & \text { Ecstatic } \\ \text { POMS } & \text { Energetic } \\ \text { PANAS } & \text { Enthusiastic } \\ \text { PANAS } & \text { Excited } \\ \text { NTAS } & \text { Friendly } \\ \text { ADHOC } & \text { Glad* } \\ \text { NTAS } & \text { Good* } \\ \text { ADHOC } & \text { Gratified* } \\ \text { NTAS/DEQ } & \text { Happy* } \\ \text { ADHOC } & \text { Hopeful } \\ \text { ADHOC } & \text { In Love } \\ \text { PANAS } & \text { Inspired } \\ \text { PANAS } & \text { Interested } \\ \text { ADHOC } & \text { Joy } \\ \text { ADHOC } & \text { Laid-back }\end{array}$




$\begin{array}{ll}\text { POMS } & \text { Lively } \\ \text { NTAS } & \text { Pleasant }^{*} \\ \text { ADHOC } & \text { Pleased }^{*} \\ \text { PANAS } & \text { Proud }^{*} \\ \text { ADHOC } & \text { Relaxed } \\ \text { ADHOC } & \text { Rewarded } \\ \text { ADHOC } & \text { Satisfied } \\ \text { ADHOC } & \text { Serene } \\ \text { PANAS } & \text { Strong } \\ \text { DEQ } & \text { Thankful } \\ \text { ADHOC } & \text { Tranquil }\end{array}$


Supplemental Table 8. Original items of the Positive Affect During Aggression Scale and their associated component loadings from the EFA from Study 7. *Retained in final 9-item Aggressive

Pleasure subscale.

\begin{tabular}{|c|c|c|c|c|c|}
\hline Original & Component & Component & Component & Component & Component \\
\hline Scale Items & 1 & 2 & 3 & 4 & 5 \\
\hline Active & .00 & .05 & .04 & .09 & .35 \\
\hline Alert & .10 & -.06 & -.05 & .04 & .64 \\
\hline Anticipation & -.02 & -.13 & .22 & .06 & .26 \\
\hline At peace & .36 & .47 & -.02 & .09 & .15 \\
\hline Attentive & -.03 & .19 & .08 & -.07 & .66 \\
\hline Blessed & .02 & .05 & .37 & .43 & .12 \\
\hline Calm & .07 & .77 & -.09 & .03 & .07 \\
\hline Carefree & -.04 & .73 & -.03 & -.01 & -.01 \\
\hline Delighted ${ }^{*}$ & .62 & .05 & .21 & -.03 & -.01 \\
\hline Determined & .01 & .05 & .18 & .12 & .40 \\
\hline Ecstatic & .18 & -.10 & .63 & .13 & -.12 \\
\hline
\end{tabular}




$\begin{array}{lccccc}\text { Energetic } & -.10 & .05 & .60 & .17 & .17 \\ \text { Enthusiastic } & .38 & .03 & .26 & .01 & .02 \\ \text { Excited } & .38 & .08 & .22 & -.09 & .00 \\ \text { Friendly } & .30 & .31 & -.09 & .27 & .13 \\ \text { Glad* } & .75 & -.08 & .03 & .04 & .05 \\ \text { Good }^{\star} & .67 & .26 & -.04 & .08 & .07 \\ \text { Gratified }^{*} & .54 & -.05 & .07 & .07 & .08 \\ \text { Happy* } & .76 & .19 & -.04 & .00 & .07 \\ \text { Hopeful } & .14 & .00 & .11 & .46 & .14 \\ \text { In Love } & -.04 & .06 & .25 & .29 & .03 \\ \text { Inspired } & .31 & .04 & .21 & .00 & .18 \\ \text { Interested } & .04 & .20 & -.09 & .02 & .04 \\ \text { Joy } & .30 & -.01 & .21 & .48 & -.15 \\ \text { Laid-back } & .01 & .78 & .07 & -.04 & -.07 \\ \text { Lively } & .01 & .07 & .59 & .11 & .09 \\ \text { Pleasant } & .63 & .18 & .05 & .13 & .00\end{array}$




\begin{tabular}{lccccc} 
Pleased $^{*}$ & .70 & .03 & .07 & .06 & .05 \\
Proud $^{*}$ & .54 & .01 & -.04 & .22 & .09 \\
Relaxed & .05 & .76 & -.02 & .12 & .05 \\
Rewarded & .24 & .12 & .17 & .12 & -.06 \\
Satisfied & .66 & .10 & -.01 & .02 & .10 \\
Serene & .29 & .31 & .27 & .04 & .27 \\
Strong & .20 & .01 & .01 & .15 & .44 \\
Thankful & -.06 & .02 & -.02 & .92 & -.01 \\
Tranquil & .18 & .47 & .31 & .00 & .13 \\
\hline
\end{tabular}


Supplemental Table 9. Descriptive statistics and internal scale consistencies for key variables from Study 4. HPFS = History of Physical Fights, HSAT = Hot Sauce Aggression Task, PADAS = Positive Affect During Aggression Scale, SSIS = Short Sadistic Impulse Scale, VDAT = Voodoo Doll Aggression Task.

\begin{tabular}{|c|c|c|c|c|c|c|}
\hline Measure & $M$ & $S D$ & $\begin{array}{l}\text { Observed } \\
\text { Minimum }\end{array}$ & $\begin{array}{l}\text { Observed } \\
\text { Maximum }\end{array}$ & $\alpha$ & Missing Data $N$ \\
\hline HPFS - Past Five Years & 0.79 & 1.50 & 0.00 & 10.00 & $\mathrm{n} / \mathrm{a}$ & 11 \\
\hline HPFS - Past Year & 0.21 & 0.66 & 0.00 & 5.00 & $\mathrm{n} / \mathrm{a}$ & 6 \\
\hline HSAT (Log Transformed) & 0.56 & 0.33 & 0.00 & 1.43 & $\mathrm{n} / \mathrm{a}$ & 8 \\
\hline SSIS (10 items) & 1.48 & 0.53 & 1.00 & 4.10 & .62 & 29 \\
\hline SSIS (9 items) & 1.29 & 0.50 & 1.00 & 4.11 & .77 & 29 \\
\hline Taylor Aggression Paradigm & 5.10 & 2.01 & 0.00 & 10.00 & .98 & 0 \\
\hline
\end{tabular}


Supplemental Table 10. Zero-order correlations between key variables from Study 4. HPFS = History of Physical Fights, HSAT = Hot Sauce Aggression Task, PADAS = Positive Affect During Aggression Scale, VDAT $=$ Voodoo Doll Aggression Task. Gender is coded: male $=1$, female $=-1 .{ }^{\star} p<.05,{ }^{\star \star} p<.01,{ }^{\star \star \star} p<.001$

\begin{tabular}{|c|c|c|c|c|c|c|c|}
\hline & 1 & 2 & 3 & 4 & 5 & 6 & 7 \\
\hline \multicolumn{8}{|l|}{ 1. Gender } \\
\hline 2. HPFS - Past Five Years & $.38^{* * *}$ & & & & & & \\
\hline 3. HPFS - Past Year & $.29^{* \star *}$ & $.78^{\star * *}$ & & & & & \\
\hline 4. HSAT (Log Transformed) & $.24^{\star \star}$ & .11 & .02 & & & & \\
\hline 5. PADAS - Pleasure & $.21^{\star *}$ & .12 & $.17^{*}$ & -.01 & & & \\
\hline 6. Short Sadistic Impulse Scale & $.23^{* *}$ & $.40^{\star \star \star}$ & $.45^{\star \star \star}$ & .06 & $.19^{*}$ & & \\
\hline 7. Taylor Aggression Paradigm & -.11 & -.04 & .20 & .09 & $-.16^{\star *}$ & $.19^{*}$ & \\
\hline 8. VDAT (Log Transformed) & $-.16^{\star}$ & -.06 & .01 & -.00 & $.17^{*}$ & .14 & $.38^{\star \star *}$ \\
\hline
\end{tabular}


Supplemental Table 11. Descriptive statistics and internal scale consistencies for key variables from Study 5. BAQ = Brief Aggression Questionnaire, NTS = Need Threat Scale, VDAT = Voodoo Doll Aggression Task. 'Pre', 'During', and 'Post' refer to before, during, and after participants completed the aggression measure, respectively.

\begin{tabular}{|c|c|c|c|c|c|c|}
\hline Measure & $M$ & $S D$ & $\begin{array}{l}\text { Observed } \\
\text { Minimum }\end{array}$ & $\begin{array}{l}\text { Observed } \\
\text { Maximum }\end{array}$ & $\alpha$ & Missing Data $N$ \\
\hline BAQ - Anger & 3.05 & 1.45 & 1.00 & 6.33 & .73 & 1 \\
\hline BAQ - Hostility & 3.63 & 1.50 & 1.00 & 7.00 & .76 & 1 \\
\hline BAQ - Physical Aggression & 3.48 & 1.82 & 1.00 & 7.00 & .83 & 1 \\
\hline BAQ - Verbal Aggression & 4.41 & 1.32 & 1.00 & 7.00 & .68 & 1 \\
\hline NTS - Negative Affect (Pre) & 2.88 & 1.67 & 1.00 & 6.33 & .87 & 1 \\
\hline NTS - Positive Affect (Pre) & 4.70 & 1.71 & 1.00 & 7.00 & .92 & 1 \\
\hline NTS - Negative Affect (During) & 3.65 & 1.67 & 1.00 & 7.00 & .81 & 1 \\
\hline NTS - Positive Affect (During) & 3.63 & 1.98 & 1.00 & 7.00 & .95 & 1 \\
\hline NTS - Negative Affect (Post) & 2.59 & 1.59 & 1.00 & 7.00 & .86 & 1 \\
\hline NTS - Positive Affect (Post) & 4.94 & 1.61 & 1.00 & 7.00 & .93 & 1 \\
\hline Short Sadistic Impulse Scale & 2.00 & 1.18 & 1.00 & 5.80 & .90 & 1 \\
\hline
\end{tabular}


$\mathrm{n} / \mathrm{a}$ 
Supplemental Table 12. Zero-order correlations between key variables from Study 5. BAQ = Brief Aggression Questionnaire, NTS = Need Threat Scale, SSIS = Short Sadistic Impulse Scale, VDAT = Voodoo Doll Aggression Task.

Gender is coded: male = 1, female = -1. 'Pre', 'During', and 'Post' refer to before, during, and after participants completed the aggression measure, respectively. ${ }^{\star} p<.05,{ }^{\star \star} p<.01,{ }^{\star \star \star} p<.001$

$\begin{array}{llllllllllll}1 & 2 & 3 & 4 & 5 & 6 & 7 & 8 & 9 & 10 & 11 & 12\end{array}$

\begin{tabular}{|c|c|c|c|c|c|c|c|c|c|}
\hline 1. BAQ - Anger & & & & & & & & & \\
\hline 2. BAQ - Hostility & $.54^{\star \star *}$ & & & & & & & & \\
\hline 3. BAQ - Physical Aggression & $.44^{\star \star *}$ & $.44^{\star \star \star}$ & & & & & & & \\
\hline 4. BAQ - Verbal Aggression & $.39^{* * *}$ & $.41^{\star \star \star}$ & $.51^{\star \star \star}$ & & & & & & \\
\hline 5. Gender & $.19^{*}$ & .08 & $.28^{* * *}$ & $.23^{\star *}$ & & & & & \\
\hline 6. NTS - Negative Affect (Pre) & $.31^{* \star *}$ & $.29^{\star \star \star}$ & .15 & -.01 & -.01 & & & & \\
\hline 7. NTS - Positive Affect (Pre) & -.10 & -.16 & -.05 & .13 & .11 & $-.61^{* * *}$ & & & \\
\hline $\begin{array}{l}\text { 8. NTS - Negative Affect } \\
\text { (During) }\end{array}$ & .12 & .05 & .07 & .08 & .05 & $.19^{*}$ & .08 & & \\
\hline $\begin{array}{l}\text { 9. NTS - Positive Affect } \\
\text { (During) }\end{array}$ & .15 & $.20^{*}$ & $.21^{* *}$ & .13 & .12 & $.23^{\star *}$ & .00 & $-.24^{\star \star}$ & \\
\hline $\begin{array}{l}\text { 10. NTS - Negative Affect } \\
\text { (Post) }\end{array}$ & $.42^{\star \star \star}$ & $.33^{* * \star}$ & $.25^{\star *}$ & $.17^{*}$ & .07 & $.66^{\star \star \star}$ & $-.23^{\star *}$ & $.40^{\star * \star}$ & $.18^{*}$ \\
\hline
\end{tabular}


11. NTS - Positive Affect (Post)

$-.11$

$$
-.07
$$

.06

$.11 \quad .12-.35^{\star * *}$

$.59^{* * *}$

$-.18^{*}$

$.32^{\star \star *}-.33^{\star \star \star}$

12. SSIS

$.55^{\star \star \star} \quad .52^{\star \star \star} \quad .43^{\star \star \star} \quad .37^{\star \star \star} \quad .10$

$.35^{\star * \star}$

$-.12 \quad .04$

$.30^{\star * *} \quad .41^{\star * *} \quad-.02$

13. VDAT (Log Transformed)

$.27^{\star *} \quad .38^{\star \star *} \quad .29^{\star \star} \quad .09$

$.02 .43^{\star \star \star}$

$-.25^{\star \star} \quad .02$

$.44^{\star \star \star} \quad .41^{\star \star \star} \quad-.00 \quad .46^{\star \star \star}$ 
Supplemental Table 13. Descriptive statistics and internal scale consistencies for key variables from Study 6. PANAS = Positive Affect Negative Affect Schedule, SSIS = Short Sadistic Impulse Scale, VDAT = Voodoo Doll Aggression Task. 'Pre', 'During', and 'Post' refer to before, during, and after participants completed the aggression measure, respectively.

\begin{tabular}{lllllll}
\hline Measure & $M$ & $S D$ & Observed Minimum & Observed Maximum & $\alpha$ & Missing Data N \\
\hline PANAS - Negative Affect (Pre) & 1.63 & 0.71 & 1.00 & 5.00 & .83 & 1 \\
PANAS - Positive Affect (Pre) & 3.94 & 1.33 & 1.00 & 7.00 & .92 & 1 \\
PANAS - Negative Affect (During) & 1.89 & 0.82 & 1.00 & 4.30 & .87 & 0 \\
PANAS - Positive Affect (During) & 2.12 & 0.96 & 1.00 & 5.00 & .93 & 0 \\
PANAS - Negative Affect (Post) & 1.58 & 0.71 & 1.00 & 5.00 & .83 & 0 \\
PANAS - Positive Affect (Post) & 3.45 & 1.41 & 1.00 & 7.00 & .93 & 0 \\
SSIS (Ten Items) & 1.47 & 0.52 & 1.00 & 3.40 & .64 & 0 \\
SSIS (Nine Items) & 1.36 & 0.50 & 1.00 & 3.67 & .72 & 0 \\
VDAT (Log Transformed) & 0.63 & 0.64 & 0.00 & 1.72 & $\mathrm{n} / \mathrm{a}$ & 1 \\
\hline
\end{tabular}


Supplemental Table 14. Zero-order correlations between key variables from Study 6. PANAS = Positive Affect Negative Affect Schedule, VDAT = Voodoo Doll Aggression Task. Gender is coded: male = 1, female = -1. 'Pre', 'During', and 'Post' refer to before, during, and after participants completed the aggression measure, respectively. ${ }^{\star} p<.05,{ }^{\star \star} p<.01,{ }^{\star \star \star} p<.001$

\begin{tabular}{|c|c|c|c|c|c|c|c|c|}
\hline & 1 & 2 & 3 & 4 & 5 & 6 & 7 & 8 \\
\hline \multicolumn{9}{|l|}{ 1. Gender } \\
\hline 2. PANAS - Negative Affect (Pre) & .01 & & & & & & & \\
\hline 3. PANAS - Positive Affect (Pre) & $.25^{\star \star *}$ & -.10 & & & & & & \\
\hline 4. PANAS - Negative Affect (During) & -.06 & $.35^{\star \star *}$ & .10 & & & & & \\
\hline 5. PANAS - Positive Affect (During) & $.14^{*}$ & $.14^{*}$ & $.35^{\star * *}$ & .09 & & & & \\
\hline 6. PANAS - Negative Affect (Post) & .06 & $80^{* * *}$ & -.07 & $.48^{\star \star *}$ & $.13^{*}$ & & & \\
\hline 7. PANAS - Positive Affect (Post) & $.21^{* *}$ & $-.13^{*}$ & $.82^{* * *}$ & .08 & $.38^{* * *}$ & -.10 & & \\
\hline 8. Short Sadistic Impulse Scale & $.31^{* * *}$ & $.27^{\star \star \star}$ & .03 & .09 & $.18^{\star *}$ & $.31^{\star \star *}$ & .01 & \\
\hline 9. VDAT (Log Transformed) & .04 & .12 & .02 & $.19^{\star *}$ & $.25^{\star * \star}$ & .10 & -.02 & $.21^{\star *}$ \\
\hline
\end{tabular}


Supplemental Table 15. Original items from Victim Suffering Scale and their associated component loadings from the PCA in Study 7. *Used in Study 8's manipulation check.

\begin{tabular}{llll}
\hline $\begin{array}{l}\text { The pins that I placed in the doll that represented } \\
\text { my partner... }\end{array}$ & Factor 1 & Factor 2 & $\begin{array}{l}\text { Included in final } \\
\text { VSS? }\end{array}$ \\
\hline $\begin{array}{l}\text { really hurt them. }{ }^{*} \\
\text { caused them to feel real pain. [Study 8: caused }\end{array}$ & .82 & -.05 & Yes \\
them real harm] & .89 & -.04 & Yes \\
failed to harm them. & .05 & .75 & No \\
were painful to them. ${ }^{*}$ & .83 & -.07 & Yes \\
didn't hurt them. & -.10 & .86 & No \\
inflicted actual damage to them. & .88 & .07 & Yes \\
made them feel pain. & .89 & -.05 & Yes \\
pained them. & .91 & -.05 & Yes \\
caused them to suffer. & .92 & .02 & Yes \\
inflicted a real wound in them. & .90 & .11 & Yes \\
\hline
\end{tabular}


Supplemental Table 16. Descriptive statistics and internal scale consistencies for key variables from Study 7. PADAS = Positive Affect During Aggression Scale, VDAT = Voodoo Doll Aggression Task.

\begin{tabular}{lllllll}
\hline Measure & $M$ & $S D$ & Observed Minimum & Observed Maximum & $\alpha$ & Missing Data N \\
\hline Sadism Index & 0.19 & 0.57 & -0.23 & 3.15 & .95 & 0 \\
PADAS - Arousal & 2.55 & 1.45 & 1.00 & 7.00 & .80 & 0 \\
PADAS - Calmness & 3.18 & 1.79 & 1.00 & 7.00 & .87 & 0 \\
PADAS - Pleasure & 2.42 & 1.58 & 1.00 & 7.00 & .95 & 0 \\
VDAT (Log Transformed) & 0.52 & 0.61 & 0.00 & 1.72 & $\mathrm{n} / \mathrm{a}$ & 0 \\
Victim Suffering Scale & 1.99 & 1.50 & 1.00 & 7.00 & .97 & 0 \\
\end{tabular}


Supplemental Table 17. Zero-order correlations between key variables from Study 7. DD = Dirty Dozen Questionnaire, PADAS $=$ Positive Affect During Aggression Scale, VDAT = Voodoo Doll Aggression Task. Gender is coded: male $=1$, female $=-1 .{ }^{*} p<$ $.05,{ }^{\star \star} p<.01,{ }^{\star \star \star} p<.001$

\begin{tabular}{|c|c|c|c|c|c|c|c|c|c|}
\hline Measure & 1 & 2 & 3 & 4 & 5 & 6 & 7 & 8 & 9 \\
\hline \multicolumn{10}{|l|}{ 1. Gender } \\
\hline 2. Sadism Index & $.18^{* *}$ & & & & & & & & \\
\hline 3. DD - Machiavellianism & .08 & $.51^{\star \star \star}$ & & & & & & & \\
\hline 4. DD - Narcissism & $.12^{*}$ & $.58^{* * *}$ & $.61^{* * *}$ & & & & & & \\
\hline 5. DD - Psychopathy & $.11^{*}$ & $.34^{* * *}$ & $.56^{\star \star \star}$ & $.40^{\star \star *}$ & & & & & \\
\hline 6. PADAS - Arousal & $.17^{\star *}$ & $.22^{* * *}$ & .06 & .07 & $.11^{*}$ & & & & \\
\hline 7. PADAS - Calmness & $.16^{* *}$ & $.15^{\star *}$ & .08 & .06 & .07 & $.46^{\star \star *}$ & & & \\
\hline 8. PADAS - Pleasure & $.18^{* *}$ & $.19^{\star \star \star}$ & .07 & .04 & $.11^{*}$ & $.64^{\star \star *}$ & $.63^{\star \star \star}$ & & \\
\hline 9. VDAT (Log Transformed) & $.12^{*}$ & $.14^{* *}$ & .03 & .03 & -.06 & .06 & .04 & .03 & \\
\hline 10. Victim Suffering Scale & $.11^{*}$ & $.26^{* * *}$ & .08 & $.11^{*}$ & .04 & $.23^{* * *}$ & .02 & .08 & $.34^{* * *}$ \\
\hline
\end{tabular}


Supplemental Table 18. Descriptive statistics and internal scale consistencies for key variables from Study 8. PADAS = Positive Affect During Aggression Scale .

\begin{tabular}{lcclllll}
\hline Measure & $M$ & $S D$ & Observed Minimum & Observed Maximum & $\alpha$ & Missing Data N \\
\hline Sadism Index & 0.00 & 0.52 & -0.44 & 2.77 & .85 & 0 \\
PADAS - Pleasure & 3.25 & 1.42 & 1.00 & 7.00 & .96 & 2 \\
Taylor Aggression Paradigm & 4.33 & 1.87 & 0.00 & 9.74 & .98 & 3 & \\
Victim Suffering Scale & 2.19 & 1.33 & 1.00 & 7.00 & .88 & 2 \\
\hline
\end{tabular}


Supplemental Table 19. Zero-order correlations between key variables from Study 8. PADAS = Positive Affect During Aggression Scale, SD3 = Short Dark Triad Scale, TAP = Taylor Aggression Paradigm, VSS = Victim

Suffering Scale (short version). Gender is coded: male $=1$, female $=-1 .{ }^{\star} p<.05,{ }^{\star \star} p<.01,{ }^{\star \star \star} p<.001$

\begin{tabular}{|c|c|c|c|c|c|c|c|}
\hline Measure & 1 & 2 & 3 & 4 & 5 & 6 & 7 \\
\hline \multicolumn{8}{|l|}{ 1. Gender } \\
\hline 2. Sadism Index & $.27^{\star \star \star}$ & & & & & & \\
\hline 3. PADAS - Pleasure & .08 & -.01 & & & & & \\
\hline 4. SD3 - Machiavellianism & .13 & $.38^{\star \star *}$ & -.03 & & & & \\
\hline 5. SD3 - Narcissism & .10 & .09 & $.14^{*}$ & $.24^{\star *}$ & & & \\
\hline 6. SD3 - Psychopathy & $.18^{\star *}$ & $.59^{* * *}$ & -.03 & $.52^{* * *}$ & $.22^{* *}$ & & \\
\hline 7. Taylor Aggression Paradigm & .07 & .04 & .04 & $.14^{\star}$ & $.26^{\star \star \star}$ & $.14^{*}$ & \\
\hline 8. Victim Suffering Scale & -.10 & .08 & $-.15^{\star}$ & $.20^{* *}$ & -.01 & $.16^{*}$ & $.37^{\star * \star}$ \\
\hline
\end{tabular}


Supplemental Table 20. Effect sizes and sample sizes entered into internal meta-analysis.

\begin{tabular}{llll}
\hline Study & Effect Size $(r)$ & Sample Size $(n)$ & Aggression Measure \\
\hline 1 & .25 & 147 & Noise Blasts \\
2 & .16 & 149 & Hot Sauce \\
3 & .18 & 125 & Gruesome Images \\
4 & .19 & 182 & Noise Blasts \\
5 & .46 & 152 & Voodoo Doll Pins \\
6 & .21 & 237 & Voodoo Doll Pins \\
7 & .14 & 356 & Voodoo Doll Pins \\
8 & .04 & 204 & Noise Blasts \\
\hline
\end{tabular}




\section{Methodology Attachment}

\section{"Sadism and Aggressive Behavior: Inflicting Pain to Feel Pleasure"}

-----Study 1----

\section{Cover Story:}

Caffeine and placebo conditions: "The purpose of this study is to investigate how caffeine affects cognition. To do so, you will consume two pills containing either $200 \mathrm{mg}$ of caffeine or a corn starch placebo. You will not be told which one you have consumed until the end of the study. After you take the pills, you will fill out a series of questionnaires, watch a short video, perform a word identification task, perform a shape identification task, complete a language task, and play a reaction time game."

Control condition: "The purpose of this study is to investigate how caffeine affects cognition. You are a member of our control group and will not receive caffeine. In this study, you will fill out a series of questionnaires, watch a short video, perform a word identification task, perform a shape identification task, complete a language task, and play a reaction time game."

\section{Independent Variables:}

-Experimental Provocation Manipulation experimenter script:

1. "Now we will move on to the anagram task. Anagrams are words with scrambled letters. Your goal in this task is to unscramble the letters so that they form an actual word in the English language, as fast as you can."

2. Hand them an anagrams form.

3. Say "Here is the sheet with the anagrams you will complete. There are $\mathbf{1 4}$ to complete and they are all solvable. I will come back in several minutes to collect your responses."

4. Leave the room and time 3 minutes.

5. Come back into the room and WITHOUT LOOKING AT THE SCRIPT, say "You are not done yet? .............. Okay, I will give you some more time."

6. Leave the room and time 1 minute and 30 seconds. 
7. Re-enter the room and WITHOUT LOOKING AT THE SCRIPT say, "Are you still not done? .............Well, because you seem to be struggling, I will give you some more time."

8. Leave the room, and time 1 minute.

9. Reenter the room and WITHOUT LOOKING AT THE SCRIPT, sigh, and say "Alright, this seems to be a waste of my time. Let's just move on to the next task."

\section{Anagram Task}

Below are 14 10-letter anagrams. Each anagram, when solved, becomes a word. In the next 5 minutes, please solve as many anagrams as possible.

1. ablsoutely:

2. s z i a n ti irg:

3. h c imoan ars:

4. $\quad \mathrm{nagzihbzs}$ :

5. $u n a b a l c n e d$ :

6. qizniutang:

7. pczeuilbid:

8. c z linivi ig: 
9. $\mathrm{mtcyhiz}$ i e d:

10. c netim teer:

11. voinclazig:

12. b m m k o g c a n:

13. $\mathrm{lu} \mathrm{merbajck \text {: }}$

14. aximaostie:

-Short Sadistic Impulse Scale (available here:

http://psycnet.apa.org/doi/10.1037/a0022400)

\section{Dependent Variables:}

-Taylor Aggression Paradigm (stimuli available here: https://osf.io/a2wft/files/)

-Need Threat Scale (available here: https://doi.org/10.1016/S0065-2601(08)00406-1)

\section{----Study 2-----}

Cover Story: The effect mental visualization abilities on taste preferences. The Cyberball task was explained as an opportunity to practice mental visualization skills and the hot sauce aggression task was explained as a means to assess taste preferences.

\section{Independent Variables:}

-Rejection Manipulation: 
Welcome to Cyberball, the Interactive Ball-Tossing Game Used for Mental Visualization! We need you to practice your mental visualization skills. We have found that the best way to do this is to have you play an on-line ball tossing game with other VCU students who are logged on at the same time.

In a few moments, you will be playing a ball tossing game with at least two VCU students over our network. To play the game, just click on the link below, which will open the game in a new internet window. The game is very simple. When the ball is tossed to you, simply click on the name of the player you want to throw it to. When the game is over, just return to this webpage and complete the rest of the study.

What is important is not your ball tossing performance, but that you MENTALLY VISUALIZE the entire experience. Imagine what the other VCU students look like. What sort of people are they? Where are you playing? Is it warm and sunny or cold and rainy? Create in your mind a complete mental picture of what might be going on if you were playing this game in real life.

Okay, ready to begin? Please click the link below:

\section{CLICK HERE}

Acceptance condition website:

http://laits.utexas.edu/cyberball/cyberball.htm?userid=agileProgger\&amp;settings=3plin \&amp;p2name=Me\&amp;pic4=images/stevejobs.png\&amp;pics=false\&amp;pic1=image s/stevejobs.png\&amp;pic3=images/mark.jpg\&amp;chat=false\&amp;p1 name=Sam\&amp ;p3name=Jordan" target="_blank" $><$ em $><$ em $><$ span style="font-

family:\&quot;Arial\&quot;,sans-serif;mso-fareast-font-

family:\&quot;TimesNewRoman\&quot;;color:navy

Rejection condition website:

http://laits.utexas.edu/cyberball/cyberball.htm?userid=agileProgger\&amp;settings=3plos \&amp;p2name=Me\&amp;pic4=images/stevejobs.png\&amp;pics=false\&amp;pic1=image s/stevejobs.png\&amp;pic3=images/mark.jpg\&amp;chat=false\&amp;p1 name=Sam\&amp ;p3name=Jordan"target="_blank"><em ><em ><spanstyle="fontfamily:\&quot;Arial\&quot;, sans-serif;mso-fareast-font-family:\&quot;Times New Roman\&quot;;color:navy -Short Sadistic Impulse Scale (see Study 1) 


\section{Dependent Variables:}

-Hot Sauce Aggression Task (instructions and stimuli of hot sauce bottles used available here: https://osf.io/a2wft/files/)

-Need Threat Scale (see Study 1)

\section{----Study 3-----}

Cover Story: "This study is an online survey about individuals' ability to mentally visualize events." The Cyberball task was explained as an opportunity to practice mental visualization skills and the cover story for the aggression measure is depicted in the 'Dependent Variables' section below.

\section{Independent Variables:}

-Rejection manipulation (see Study 2)

-Short Sadistic Impulse Scale (see Study 1)

\section{Dependent Variables:}

-Gruesome image aggression task:

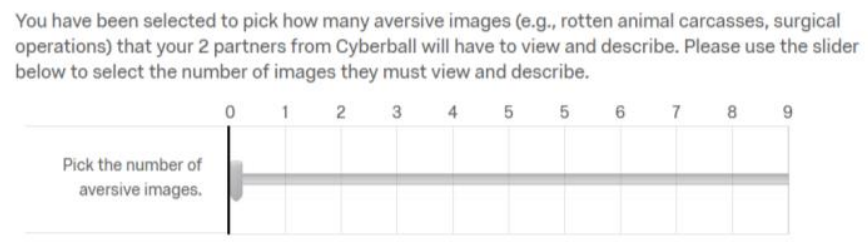

Are you sure this is the number of images you want your Cyberball partners to view and describe?

Yes, I am sure.

-Need Threat Scale (see Study 1)

----Study 4----

Cover Story: This is detailed in the experimenter script available here:

https://osf.io/a2wft/files/

Independent Variables: 
-Experimental provocation materials and scripts are available here:

https://osf.io/a2wft/files/

-Short Sadistic Impulse Scale (see Study 1)

-Positive Affect During Aggression Scale (see Supplemental Table 1)

Dependent Variables:

-Stimuli and experimenter scripts for all dependent variables are available here:

https://osf.io/a2wft/files/

\section{----Study 5-----}

Cover Story: "This online study is about individuals' ability to mentally visualize events and write about them." The essay manipulation cover story is detailed below in the 'Independent Variables' section. The voodoo doll aggression task was introduced as an opportunity to "interact with a virtual avatar to release pent up energy, this will take approximately 5 minutes."

\section{Independent Variables:}

-Short Sadistic Impulse Scale (see Study 1)

-Essay manipulation:

Now we wish to assess your writing abilities by having you write a short essay. For this task you will have a same-gender partner who is also completing this study online. You will be reviewing each others' essays to give us an idea of how skilled you are at writing about an event you had to mentally visualize.

In the space below, We would like you to write an essay about a situation that made you very angry. Please include as many details as you can. Your essay needs to be at least 800 characters (a little less than one half-page) in length and will be read by the administrators of this survey to ensure that your essay was about the topic listed above. Again, you will later exchange this essay with your partner.

Please begin whenever you are ready and continue to the next page once you are finished writing. 
Below is the text of your partner's essay

"Last week I went to a party with two of my good friends. They both know that I am not really a talkative person and that parties aren't always where I am at my best. Anyways, my friends and I got to the party and they immediately started talking to some people and left me there all by myself. I hung around in a corner, not talking to anyone, waiting for them to remember me. I even approached one of them and tried to join his conversation, which I was not really comfortable with since I am rather shy, and he did the worst thing by just ignoring me. He just kept on telling his stories and completely ignored the fact that I was right there. At that point, I was so angry and disappointed with my friends for putting me in that situation. I ended up leaving the party early without them and walked home by myself. That was unfair of them to have left me high and dry."

Please use the following items to evaluate each different aspect of your partner's essay that is displayed above.

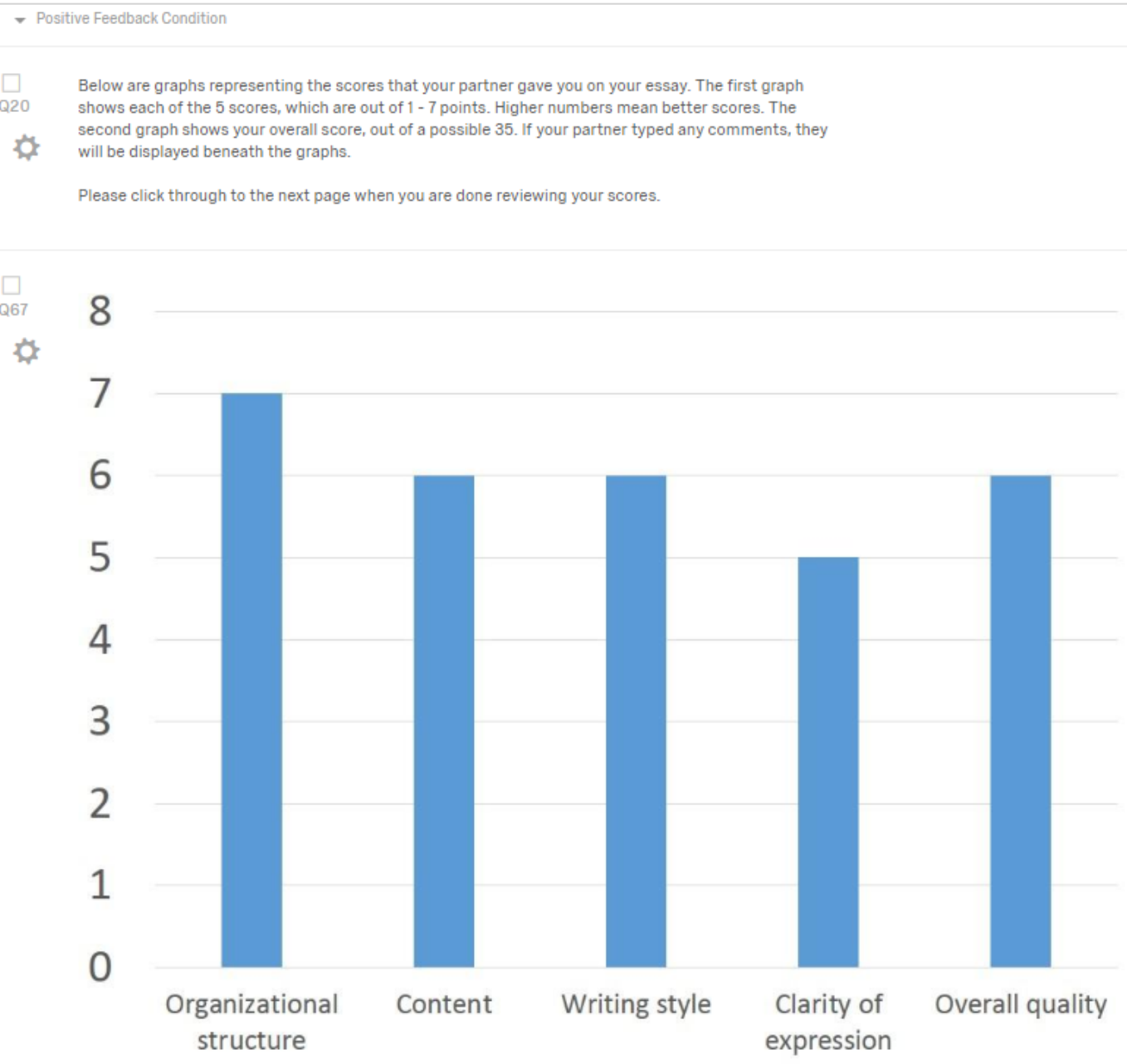


Total score

40

35

30

25

20

15

10

5

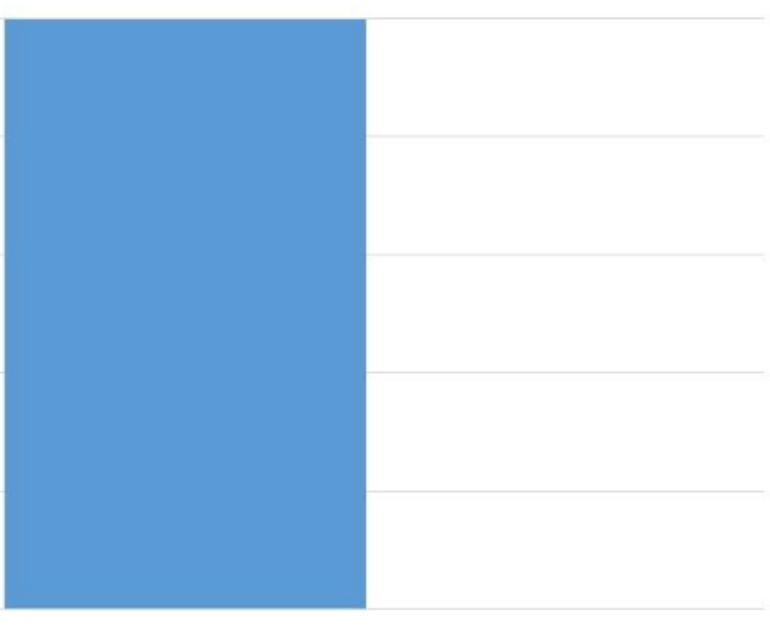

Partner comments

"Great essay!" 
Negative Feedback Condition

Below are graphs representing the scores that your partner gave you on your essay. The first graph shows each of the 5 scores, which are out of $1-7$ points. Higher numbers mean better scores. The

second graph shows your overall score, out of a possible 35 . If your partner typed any comments, they

will be displayed beneath the graphs.

Please click through to the next page when you are done reviewing your scores.

8

3

7

6

5

4

3

2

1

0

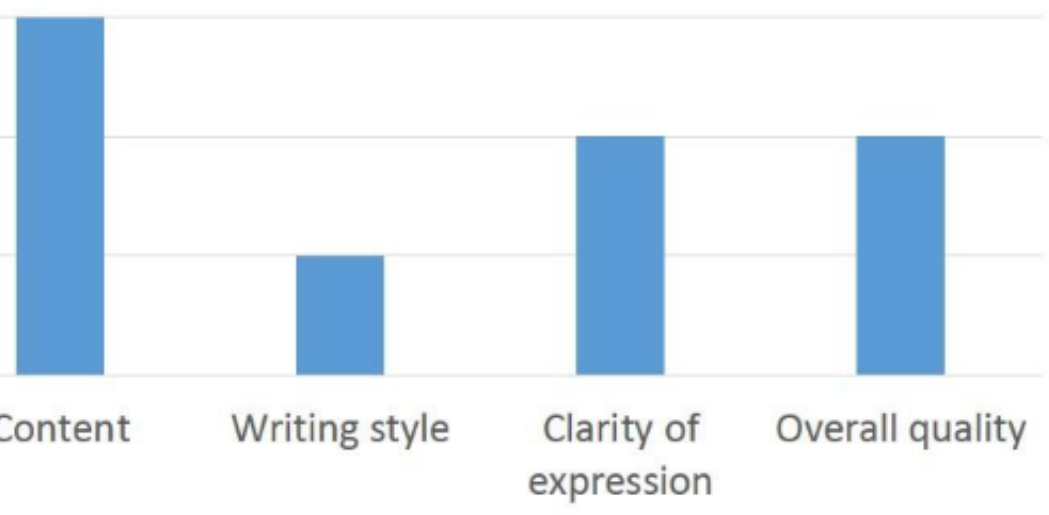

Total score 


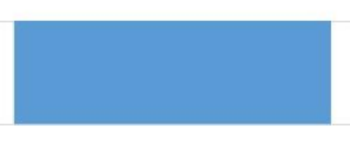

Partner comments

"One of the worst essays I have EVER read!"

\section{Dependent Variables:}

-Need Threat Scale (see Study 1)

-Voodoo Doll Aggression Task: (sample stimuli available here: https://osf.io/a2wft/files/) ----Study 6-----

Cover Story: "The purpose of this study is to investigate your cognitive and mental abilities. To do so, we will repeatedly measure your cognitive abilities which often change minute-by-minute."

The self-regulation fatigue manipulation cover story is detailed in the 'Independent Variables' section below and no cover story was given for the voodoo doll aggression measure.

Independent Variables:

-Short Sadistic Impulse Scale (see Study 1) 
-Self-control fatigue manipulation:

Experimenter script:

1. Say: "Now you will complete a short essay that will help us understand your cognitive abilities. I will give you 5 minutes to simply describe the last 3 years of your life in whatever manner you wish to do so. However, there is a catch, you are forbidden from using two letters as you write the essay. To see which letters you cannot use, please read the instructions at the top of the essay form that is in front of you."

2. Start the stopwatch and say "Please begin writing, I will ask you to stop in $\mathbf{5}$ minutes."

3. Close the door and wait out in the hallway.

4. When the stopwatch reaches 5 minutes, instruct participants to stop.

5. Collect their essay,

Control condition:

Please write a description of the last 3 years of your life, recalling key events. You will have 5 minutes to do so. While writing, you CANNOT use the letters $X$ or $Z$ at any time.

Fatigue Condition:

Please write a description of the last 3 years of your life, recalling key events. You will have 5 minutes to do so. While writing, you CANNOT use the letters $\mathrm{A}$ or $\mathrm{N}$ at any time.

\section{Dependent Variables:}

-Positive Affect Negative Affect Schedule (available here:

https://www.ncbi.nlm.nih.gov/pubmed/3397865)

-Voodoo Doll Aggression Task (see Study 5) 
Cover Story: "This study explores how your ability to imagine experiences and settings influences your responses on several computer tasks and questionnaires." The Cyberball task was explained as an opportunity to practice mental visualization skills and the voodoo doll task was explained as "a short imagination task".

\section{Independent Variables:}

-Rejection paradigm (see Study 2)

-Short Sadistic Impulse Scale (see Study 1)

-Assessment of Sadistic Personality (available here:

https://doi.org/10.1016/j.paid.2016.07.043)

-Comprehensive Assessment of Sadistic Tendencies (available here:

http://www2.psych.ubc.ca/ dpaulhus/research/DARK TRIAD/MEASURES/CAST.3.0.do

$\underline{\mathrm{CX}})$

\section{Dependent Variables:}

-Positive Affect During Aggression Scale (see Supplemental Table 1)

-Voodoo Doll Aggression Task (see Study 5)

-Victim Suffering Scale (see Supplemental Table 3)

\section{----Study 8----}

Cover Story: The study was introduced as a project meant to assess participants on a reaction-time task. Other measures were explained as potential having effects on reaction-time or are detailed in the sections below.

\section{Independent Variables:}

-Short Sadistic Impulse Scale (see Study 1) 
-Varieties of Sadistic Tendencies Scale (available here:

http://www.psych.ubc.ca/ dpaulhus/Paulhus_measures/VAST.3.3.docx)

-Victim Suffering Manipulation text and protocol is explicitly detailed in the Procedures

subsection of the Study 8 description in the manuscript.

Dependent Variables:

-Victim Suffering Scale (see Supplemental Table 3)

-Taylor Aggression Paradigm (see Study 1)

-Positive Affect During Aggression Scale (see Supplemental Table 1) 